Article

\title{
Varying VAWT Cluster Configuration and the Effect on Individual Rotor and Overall Cluster Performance
}

\author{
Jeffrey E. Silva ${ }^{1}(\mathbb{D})$ and Louis Angelo M. Danao ${ }^{2, *(\mathbb{D})}$ \\ 1 Energy Engineering Graduate Program, University of the Philippines Diliman, Quezon City 1101, Philippines; \\ jesilva@up.edu.ph \\ 2 Department of Mechanical Engineering, University of the Philippines Diliman, Quezon City 1101, Philippines \\ * Correspondence: louisdanao@up.edu.ph
}

Citation: Silva, J.E.; Danao, L.A.M. Varying VAWT Cluster Configuration and the Effect on Individual Rotor and Overall Cluster Performance. Energies 2021, 14, 1567. https:// doi.org/10.3390/en14061567

Academic Editor: Jari Hämäläinen

Received: 25 January 2021

Accepted: 9 March 2021

Published: 12 March 2021

Publisher's Note: MDPI stays neutral with regard to jurisdictional claims in published maps and institutional affiliations.

Copyright: (c) 2021 by the authors. Licensee MDPI, Basel, Switzerland. This article is an open access article distributed under the terms and conditions of the Creative Commons Attribution (CC BY) license (https:/ / creativecommons.org/licenses/by/ $4.0 /)$.

\begin{abstract}
The effect of separation distance between turbines on overall cluster performance were simulated using computational fluid dynamics software and we found that at a distance equivalent to two rotors, there was an improvement of $+8.06 \%$ in the average performance of the cluster compared to a single, isolated turbine. A very small improvement in performance was noted at the equivalent distance of 12 rotor diameters. The performances of three individual turbines in pyramid- and inverted pyramid-shaped vertical axis wind turbine clustered farm configurations with varying oblique angles at a fixed spacing of two equivalent rotor diameters were also investigated. The design experiment involves the simulation of test cases with oblique angles from $15^{\circ}$ to $165^{\circ}$ at an interval of $15^{\circ}$ and the turbines were allowed to rotate through 18 full rotations. The results show that the left and right turbines increase in performance as the angle with respect to the streamline axis increases, with the exception of the $165^{\circ}$ angle. The center turbine, meanwhile, attained its maximum performance at a $45^{\circ}$ oblique angle. The maximum cluster performance was found to be in the configuration where the turbines were oriented in a line (i.e., side by side) and perpendicular to the free-stream wind velocity, exhibiting an overall performance improvement of $9.78 \%$ compared to the isolated turbine. Other array configurations show improvements ranging from $6.58 \%$ to $9.57 \%$ compared to the isolated turbine, except in the extreme cases of $15^{\circ}$ and $165^{\circ}$, where a decrease in the cluster performance was noted due to blockage induced by the left and right turbines, and the center turbines, respectively.
\end{abstract}

Keywords: CFD; clustered wind farms; VAWT

\section{Introduction}

The spacing of individual turbines in a clustered farm affects the overall performance of the system due to the impact of changing local wind velocities brought about by the influence of the wind turbines' proximity to each other, including funneling and turbine wakes. Wake production is detrimental to the overall performance of clustered horizontal axis wind turbine (HAWT) farms, with some research finding a more than $10 \%$ loss in performance at spacing equivalent to six to ten turbine diameters in the downwind direction and a three to five turbine diameter separation in the crosswind direction [1-3]. The wake produced by the upwind turbine reduces the wind speed, as seen in the turbines located downwind, while increasing the turbulence intensity. For example, in the study of Tang et al. conducted in a wind tunnel set-up, there was a notable decrease in the performance of both the upstream and downstream turbines in two HAWTs arranged in tandem, in comparison to the performance of a single, isolated turbine simulated in the same wind tunnel [4]. The reduction of the performance of the tandem turbines ranged from $20 \%$ at an equivalent turbine diameter separation distance of 12 to more than $60 \%$ at an equivalent separation distance of one or two. Therefore, when deployed in clusters with insufficient turbine spacing, HAWTs tend to reduce the overall cluster performance due to reduced wind speed received by the downwind turbines. In contrast, recent studies show that 
wake recoveries behind vertical axis wind turbines (VAWTs) are achieved in a spacing of as few as four to six equivalent turbine diameters compared to HAWTs' 15 to 20 equivalent diameter distance $[5,6]$. Constructive aerodynamic interference from the wakes of the nearby turbines results in significant power increases due to the production of regions with excess momentum [7]. Hence, VAWTs' rapid wake recovery characteristics allow a more compact wind turbine arrangement, resulting in higher power density per unit area. Turbulence induced by the clustering of the turbine cluster might be one of the reasons for the perceived overall performance increase. A recently published study by Molina et al. found that the effect of turbulence on the performance of VAWTs is positive, increasing the coefficient of performance of NACA0018 blades by $20 \%$ when the turbulence intensity was increased from $0.5 \%$ to $15 \%$ [8]. The wind turbine's coefficient of performance, defined as the ratio of the actual power captured by the wind turbine rotor to the available power, is the usual parameter used when comparing the efficiency of wind turbines. With respect to the tip speed ratio, $\lambda$, defined as the ratio of tangential speed at the tip of the blade and the speed of the wind, there was a dramatic increase in the performance at a lower tip speed ratio $(2.6<\lambda<3.2)$ and at higher Reynolds number. The experiment was conducted in an open-circuit boundary layer wind tunnel using two different sets of passive grids to generate temporary turbulent flows at Reynolds numbers of 300,000 and 330,000. The authors concluded that the induced turbulence flow helped improve the performance of the VAWT due to delaying stalling of the blades, drag effect reduction and faster wake recovery. Meanwhile, a recent experiment of Vergaerde et al. concluded that there is a benefit to the power performance when a pair of VAWTs are placed in closed proximity [9]. In this study, performances of pairs of counter-rotating VAWTs with a turbine spacing equivalent to $1.2 \mathrm{D}$ and 1.3D were investigated in a wind tunnel experiment and compared to an isolated turbine. An inner-upwind turbine pair configuration produced a much smaller, centrally narrowed wake compared to the isolated turbine since the generated wakes of the turbine pair were deflected toward each other.

The synergistic phenomena exhibited by VAWTs when clustered as a group have been investigated in a growing number of published articles. For clustered HAWT farms, the typical power density ranges from 2 to $3 \mathrm{~W} / \mathrm{m}^{2}$ [10], but a study conducted by Dabiri [11] found out that by optimizing the placement of VAWTs, a power density of up to $30 \mathrm{~W} / \mathrm{m}^{2}$ was achieved by enabling turbines to extract energy from the wakes produced by the neighboring turbines. Brownstein et al. [6] achieved a $14 \%$ increase in array performance in the most robust array configuration studied in their open-circuit, subsonic wind tunnel experiment. A pair of five-bladed VAWTs were used in the study and simulated with different turbine spacings and directions of rotation. For both the downwind and upwind turbines, a performance increase was noted due to bluff-body accelerations induced by the upwind turbine, and the reconstruction of the surrounding flow field due to the existence of the downwind turbine.

An identical conclusion on the effect of wind turbine synergy was made by Zhang et al. [12] by combining particle swarm optimization and a numerical method with validation through experimental data. In this study, downwind turbines were seen to improve by up to $24.03 \%$ compared to the reference, i.e., the isolated turbine. Other studies showed that even the performance of the upwind turbine can be affected by the presence of the downwind turbines. Incoming wind velocity might be increased or decreased in specific upwind locations before it meets the wind park [13].

The use of computational fluid dynamics (CFD) in turbine wake modeling and individual and clustered turbine performance simulation has been gaining a foothold in recent years, with a sizable amount of current research utilizing numerical methods to further the studies in this field. CFD is especially useful in simulating flow fields for VAWTs since very few large-scale VAWTs are currently in operation, and full-scale field tests and measurement campaigns might not be feasible [14]. Some examples which use CFD to investigate the nature of VAWT wake characteristics are Samsoddin and Porte-Angel [15], who used a large eddy simulation approach for the investigation of wake characteristics 
behind a VAWT in a three-dimensional turbulent flow, and Bremseth and Duraisamy [7], who utilized the OVERTURNS solver and performed calculations using the solution of compressible URANS to simulate a single, paired, and array of VAWTs to conclude that a pair of counter- or co-rotating VAWTs were able to produce more power compared to an isolated turbine, taking advantage of the induced velocity field of the paired turbines. Peng [16], meanwhile, used OPENFOAM, open source CFD software utilizing the finite volume method, to compare the performance of two closely placed VAWT pairs and an isolated turbine. He concluded that the pairs of opposite-rotating turbines exhibit faster rotation compared with the isolated rotor in the same wind speed, hence a 70\% performance improvement was noticed at a 1.6 equivalent turbine diameter spacing. Bangga et al., meanwhile, used three CFD codes, namely, FLOWer, TAU and Ansys Fluent to predict the power curves of three different turbines with varying solidity of $\sigma=0.23,0.53$ and 1.325 [17]. In this study, the authors established that CFD show reasonable accuracy after reintegrating thrust force in comparison to the experimental data.

Although, for small wind turbines, the most effective way of examining their performance is to subject them to wind tunnel experiments because of their capability to describe the flow fields both across and behind the rotor [18], the use of numerical methods does not require huge capital cost, operational know-how and diverse technical skills [19]. Castelli et al. [20] compared the results of CFD simulations to experimental results and they concluded that numerical codes are able to replicate the results of the experimental curve and can be a reliable alternative to wind tunnel tests. Further, Barber and Nordborg found that the average power coefficient per tip speed ratio as well as the forces in the blades of small-scale VAWTs can be effectively examined by the use of detached eddy simulation (DES) [14]. More recently, there was a study wherein the performance of a $7.2 \mathrm{~kW}$ HAWT was investigated by comparing its performance through outdoor experiments involving electrical excitation of the turbine generator to measure the generated voltage and current, and the prediction used Ansys Fluent code [21]. The conclusion of the study shows that the numerical method agrees with the experiment within $5 \%$ of the computed performance coefficient within the range of $\lambda=4.0$ to 5.5. A recent paper by He et al. validated the results of their CFD simulation for Darrieus VAWT performance by using the physical equivalent of the model in a wind tunnel experiment. Good agreement between the CFD and wind tunnel results was observed, and the authors concluded that CFD modeling techniques were able to replicate the relationship of the power performance and the tip speed ratio in that particular experiment [22].

Computational fluid dynamics' fundamental basis is the Navier-Stokes equations, a set of equations which describe the motion of viscous fluid substances. The problem tackled in this study is within the incompressible region. This results in the conservation of mass and momentum equations, written as the following:

$$
\begin{gathered}
\frac{\partial u_{i}}{\partial x_{i}}=0, \\
\rho \frac{\partial u_{i}}{\partial t}+\rho u_{j} \frac{\partial u_{i}}{\partial x_{j}}=-\frac{\partial p}{\partial x_{i}}+\frac{\partial t_{j i}}{\partial x_{j}},
\end{gathered}
$$

where $u_{i}$ is velocity, $x_{i}$ is position, $t$ is time, $p$ is pressure, $\rho$ is density and $t_{i j}$ is the viscous stress tensor defined by

$$
t_{i j}=2 \mu s_{i j}
$$

where $\mu$ is molecular viscosity and $s_{i j}$ is the strain-rate tensor.

$$
s_{i j}=\frac{1}{2}\left(\frac{\partial u_{i}}{\partial x_{j}}+\frac{\partial u_{j}}{\partial x_{i}}\right)
$$


Rewriting and simplifying the previous equations yield the Navier-Stokes equation in conservation form.

$$
\rho \frac{\partial u_{i}}{\partial t}+\rho \frac{\partial}{\partial x_{j}}\left(u_{i} u_{j}\right)=-\frac{\partial p}{\partial x_{i}}+\frac{\partial}{\partial x_{j}}\left(2 \mu s_{i j}\right),
$$

Time-averaging Equations (1) and (5) yield the Reynolds-averaged equations of motion in conservation form,

$$
\begin{gathered}
\frac{\partial U_{i}}{\partial x_{i}}=0 \\
\rho \frac{\partial U_{i}}{\partial t}+\rho \frac{\partial}{\partial x_{j}}\left(U_{j} U_{i}+\overline{u_{j}^{\prime} u_{i}^{\prime}}\right)=-\frac{\partial P}{\partial x_{i}}+\frac{\partial}{\partial x_{j}}\left(2 \mu S_{j i}\right)
\end{gathered}
$$

Rewriting Equation (7) in its reverse yields its most recognizable form.

$$
\rho \frac{\partial U_{i}}{\partial t}+\rho U_{j} \frac{\partial U_{i}}{\partial x_{j}}=-\frac{\partial P}{\partial x_{i}}+\frac{\partial}{\partial x_{j}}\left(2 \mu S_{j i} \overline{\rho u^{\prime}{ }_{j} u_{i}^{\prime}}\right)
$$

Equation (8) is denoted as the Reynolds-averaged Navier-Stokes (RANS) equation, where the quantity $\overline{\rho u_{j}^{\prime} u_{i}^{\prime}}$ is the Reynolds stress tensor. The averaging process introduced unknowns, through the Reynolds stress components, necessitating additional equations to close the problem. Turbulence modeling provides the solution by devising approximations for the unknown correlations in terms of flow properties that are known so that a sufficient number of equations exist.

Most of the published literature deals with only one or two schemes of comparison when dealing with VAWT clustering, most commonly on the varying turbine distances $[3,4,9,23]$ and/or direction of turbine direction [24-26], hence the intention of this study is to integrate the important variations in a turbine cluster and illustrate their effect in a single, continuous study.

The present work will attempt to integrate the turbine cluster studies in iterations from linear turbine spacing to angular turbine spacing and, finally, to turbine rotation studies.

\section{Methodology}

\subsection{Computational Domain}

The computational domain is composed of the inner, rotating domain which represents the physical characteristics of the turbines and the stationary domain which interfaces immediately with the rotating domain and extends towards the outer boundary of the computational domain. The rotating domain was allowed to mesh through the circular opening modeled in the stationary domain at a common angular speed.

To fully capture the full development of the wake, Ferreira [27] used 10 equivalent rotor diameters upwind and 14 diameters downwind as distances away from the rotor test section in his wind tunnel experiment. As a reference for this study, as well as the due to intention to perform this simulation in an open field condition while reducing the effect of solid blockage due to the presence of the turbine, the distances from the upwind and downwind boundaries are set to 22 and 36.5 equivalent rotor diameters, respectively. The size of the computational domain is $176.675 \mathrm{~m} \times 133.35 \mathrm{~m}$. Figure 1 shows the dimensions of the computational domain.

A three-bladed Darrieus turbine with a diameter of $3.0 \mathrm{~m}$ with an airfoil cross-section described as NACA 0025 was used in this study. The blades, consisting of airfoil sections and a central hub, were modeled, while the radial arms were not considered in the domain. The blade has a chord length of $0.15 \mathrm{~m}$. The solidity, representing the fraction the blades covered with respect to the swept area, is equal to 0.15 .

To generate the mesh, the authors used Ansys-compatible meshing software, which has built-in support for Ansys Fluent, the CFD code used in this study. The meshing software allows flexibility in modifying certain mesh characteristics within previously constructed mesh through its scripting code. 


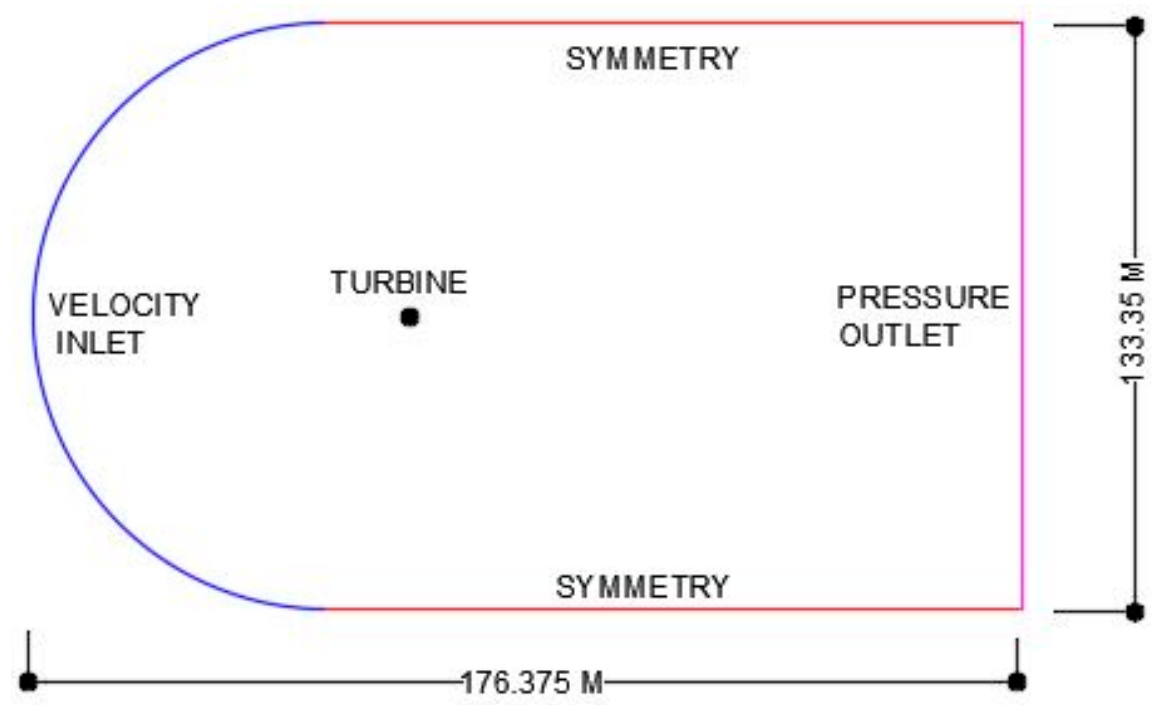

Figure 1. The computational fluid dynamics (CFD) domain for a single turbine.

The rotating domain was meshed meticulously since important flow effects happen in this domain. Finer mesh was employed (Figure 2), and the different values of the first cell height were simulated and tested in the CFD software to make sure that the resulting value of the wall unit, $\mathrm{y}^{+}$, lies in the region where the relationship between turbulent and laminar forces is linear, that is, $0<\mathrm{y}^{+}<5$. Grid refinements were done by varying the value of the first cell height and inflating it to 25 levels of prismatic cells. In the rotating domain, there were 102,000 cells. Overall, simulations containing a single turbine have 121,000 cells while there are about 332,000 cells in a domain with three turbines (Figure 3a).

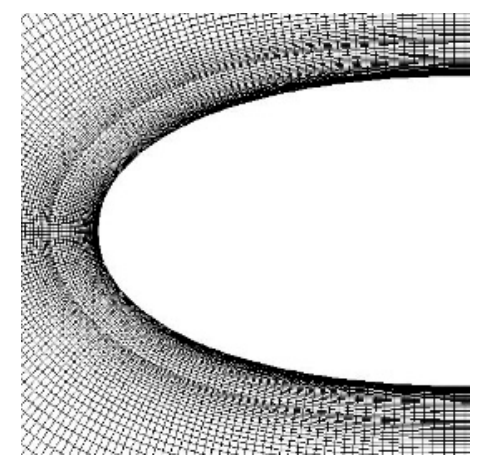

(a)

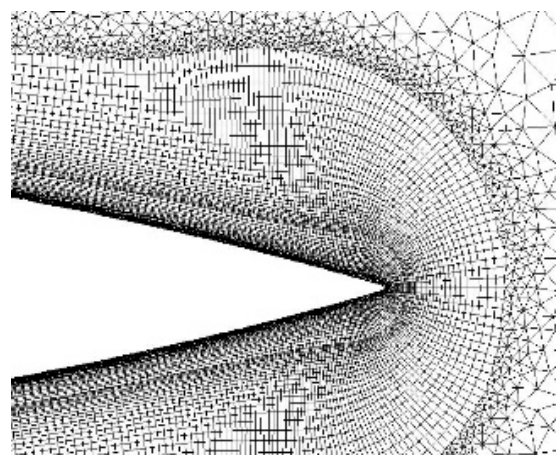

(b)

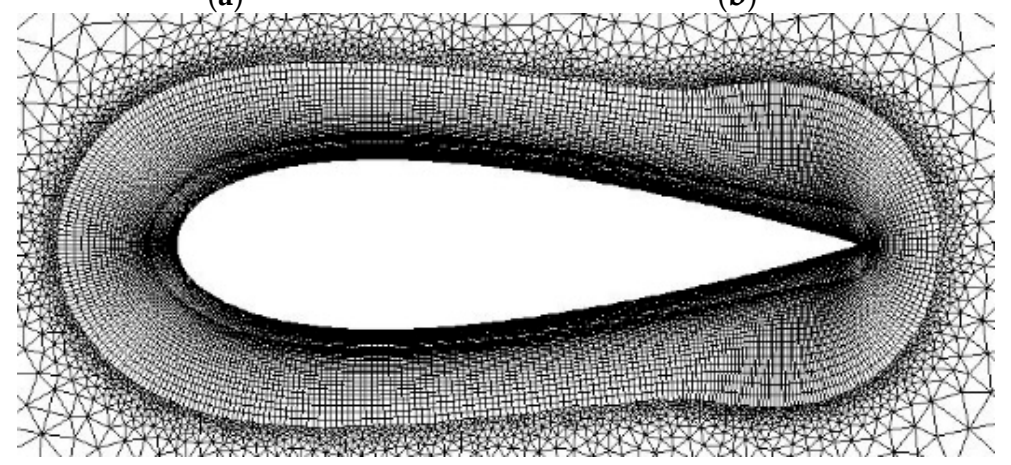

(c)

Figure 2. Near blade mesh at (a) the leading edge, (b) the trailing edge and (c) full blade mesh visualization. 


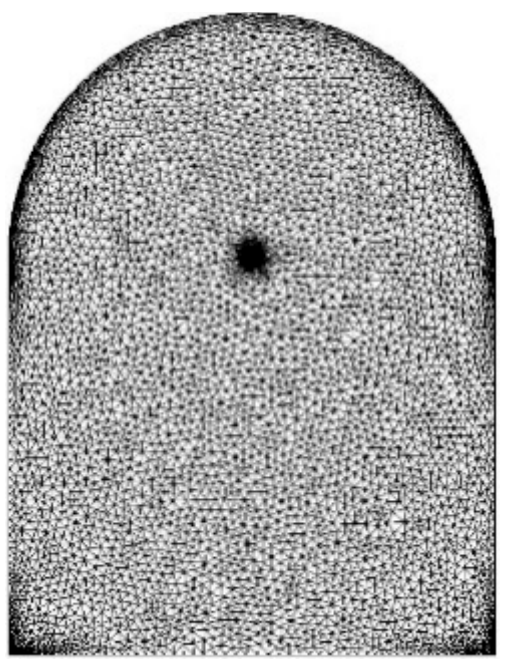

(a)

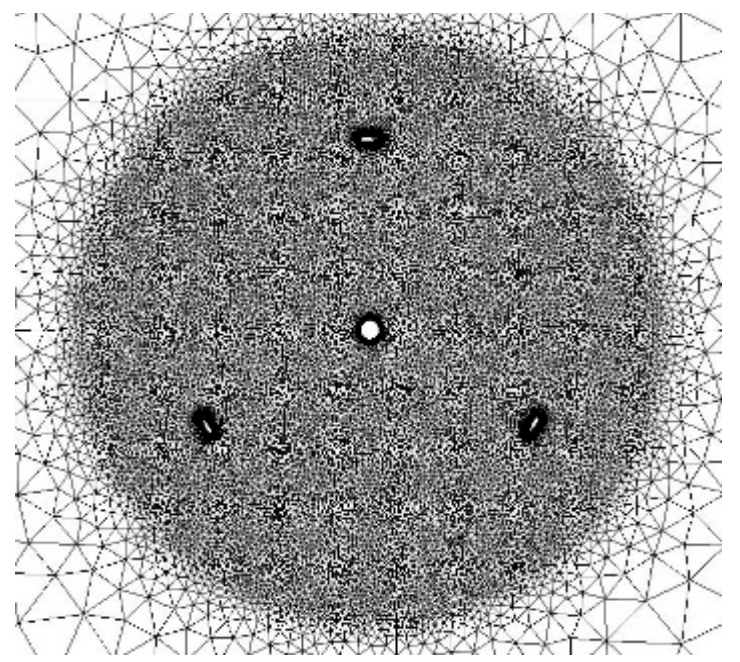

(b)

Figure 3. Unstructured mesh at (a) rotating domain and (b) outer domain.

Triangular cells were generated by inflating from the interface boundary of the stationary domain and extending up to the outer boundary with a growth rate of 1.3. There are about 19,000 cells composing the stationary domain (Figure 3b). The average aspect ratio of the cells in the domain is 1.27 , with a maximum value of 2.86 .

Aside from the value of the wall unit, another characteristic of the mesh to be examined is the equiangle skewness, defined as the maximum ratio of a cell's included angle to the angle of an equiangular element. The range of the values of the equiangular skewness is from zero to one, with zero as the best case and one as the worst case which may lead to numerical volatilities and erroneous results of the CFD simulation. In this study, the value of the maximum skewness is 0.65 for the stationary sub-domain and 0.57 for the rotating sub-domain. These extrema were likewise located on the peripheral line of the computational domain, and the average values are 0.18 and 0.08 for the stationary and rotating domain, respectively. Published literature recommends that the equiangle skewness should be kept below 0.8 [28].

To run smooth simulations of test cases, appropriate boundary conditions were defined. The area where the wind velocity is coming from was defined as velocity inlet, while the area opposite it, and leeward to the turbines, was defined as pressure outlet. The two lines flanking the turbines were defined as symmetric. This is to let the solver assume that the wall is a subset of a larger domain, effectively reducing the computational domain, and to avoid the wall effect [29]. The area meshing the stationary domain with the rotating domain is called the interface. Airfoil surfaces and the silhouette of the turbine mast were defined as walls.

The simulation was done in a two-dimensional system. Although some phenomena were not captured in 2D compared to 3D, such as tip vortices, some studies point out that simulation in 2D yields slight overestimation in the power coefficient when compared to experimental data [30].

\subsection{Turbulence Model and Solver}

The turbulence model used in all of the simulations in this study is the k- $\omega$ shear stress transport (SST), a two-equation eddy viscosity model for CFD flow. This turbulence model is a blending function which combines the versatility of the k- $\omega$ model at the inner boundary layer, then switches to the $k-\varepsilon$ model to solve the flow on the outside of the boundary layer. In general, $\varepsilon$ models are good for shear flows, while $\omega$ models are appropriate for separating flows $[3,31]$. Both types of flow will be exhibited in this study where rotating turbines are involved, hence the $k-\omega$ SST was chosen as the turbulence model to be used. It was shown in one study that k- $\omega$ SST exhibited superior performance 
in modeling vortices and capturing wake [32]. Finally, the k- $\omega$ SST turbulence model was successfully used in numerous simulations involving H-type Darrieus VAWTs [20,33,34]. While this paper wanted to capitalize on the appropriateness of the k- $\omega$ SST turbulence model, however, there is a need to consider the initial wall height, which is a requirement for blending functions [31]. This requirement was fulfilled and discussed in Section 2.1.

Ansys Fluent, a CFD package using the finite volume method to solve governing equations for fluids, was used in this study. A coupled scheme was used to solve the convection term in the URANS equation and hence used as the pressure-velocity coupling in the CFD software to solve the pressure gradient and was input as the algorithm for the spatial discretization gradient in the CFD. To reduce numerical discretization errors and solve the turbulence term, the CFD option for second-order discretization was used for the computation of pressure, momentum, turbulent kinetic energy and specific dissipation rate to achieve more accurate results. Under-relaxation factors to stabilize the convergence behavior were set to recommended values.

Control parameters, such as values of momentum, residuals, continuity, coefficients of moment, drag and lifts, were monitored for each iteration and recorded in the output file.

All cases are subjected to $5.0 \mathrm{~m} / \mathrm{s}$ of free-stream wind velocity. At $5 \mathrm{~m} / \mathrm{s}$ free-stream wind velocity, the Reynolds number based on rotor diameter is 992,654 .

A parallel processing option was utilized to maximize the computer's hardware capability and reduce the simulation's computation time. Double precision was implemented for added accuracy of results.

The effect of gravity was expected to exert very little influence on the result of the simulation and hence was not considered in the study.

\subsection{Convergence Criteria}

Each of the turbines were run through 18 full rotations and the last 3 full rotations were studied. To make sure that the results of each rotation converged to almost the same value and no further rotation was needed to guarantee the accuracy, the last three rotations (i.e., 16th, 17 th and 18th rotations) were compared. The calculated coefficient of performance values, $\mathrm{Cp}$, of the last three rotations should agree to within $\pm 3 \%$ while all monitored residuals should fall within $1.0 \times 10^{-5}$. It is also important to check the trend of the values of other parameters; it should be an oscillating trend which is typical for transient simulations [31].

\subsection{Time Step Independence Study and Tip Speed Ratio Simulation}

With the measurement of turbulence happening during the rotations of wind turbines and wake interactions, there is a need to reduce the time scale of the turbulence to reflect the accuracy of results we want to achieve. However, a trade-off between the accuracy of the results and the efficiency of calculations should be made since too fine a scale of time will result in more accurate results but longer simulation times, while too great a time step will lead to inaccurate results [31].

A simulation was first performed for tip speed ratio, $\lambda=4$, at three different values of temporal resolution $\left(0.5^{\circ} \omega^{-1}, 1.0^{\circ} \omega^{-1}, 2.0^{\circ} \omega^{-1}\right)$. At this point of the study, the tip speed ratio is included in the investigation of wind turbine performance since wind turbines should operate at the speed where this ratio is optimum. Slowly rotating turbines will let the wind pass through the blades unperturbed, while fast-rotating turbines limit the angles of attack of the blades to low values, reducing lift and, subsequently, power extraction.

Fifty iterations per time step were used and a single turbine was made to run for 18 rotations. It was found out that the variations in the computed $\mathrm{Cp}$ for the three initial simulations only ranged from $0.19 \%$ to $0.47 \%$. Further simulations at the same set of temporal resolutions but $\lambda=3,4$ and 5 were performed with variation across the time steps of only $0 \%$ to $2.3 \%$ (Figure 4 ). Since there was a negligible difference in the computed Cps across different temporal resolutions, the time step size of $2.0^{\circ}$ was considered for subsequent simulations. This was to reduce the computational time without compromising 
the accuracy of the results. A comparison to previous studies of the calculated $\mathrm{Cp}$ at different tip speed ratios was performed and is shown in Figure 5. One can notice that the trend is generally in agreement with previously published studies.

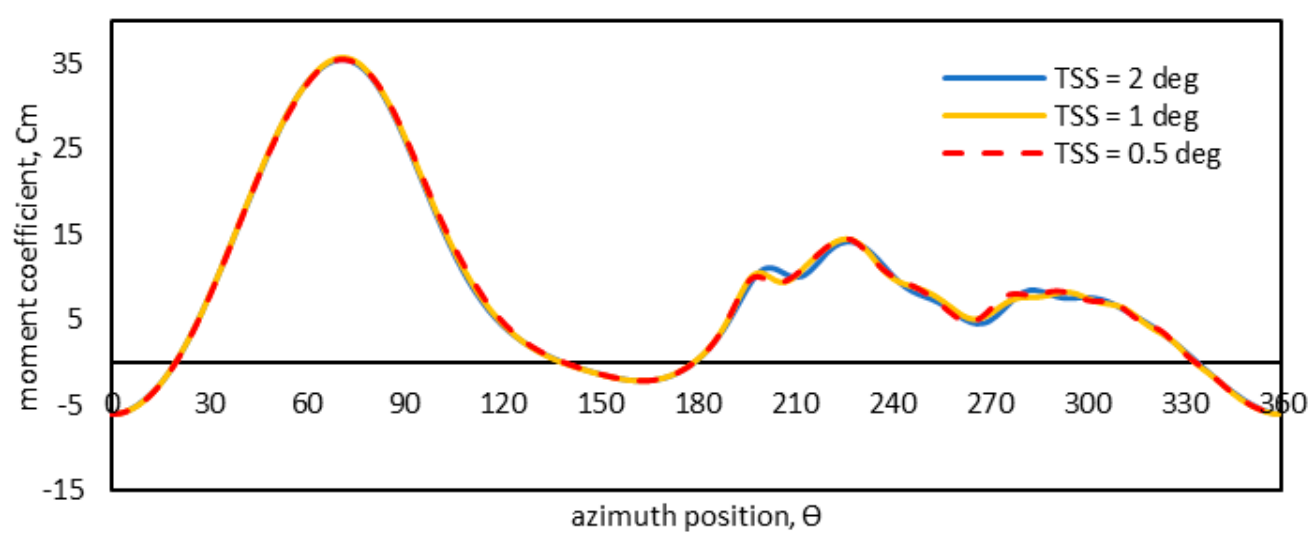

(a)

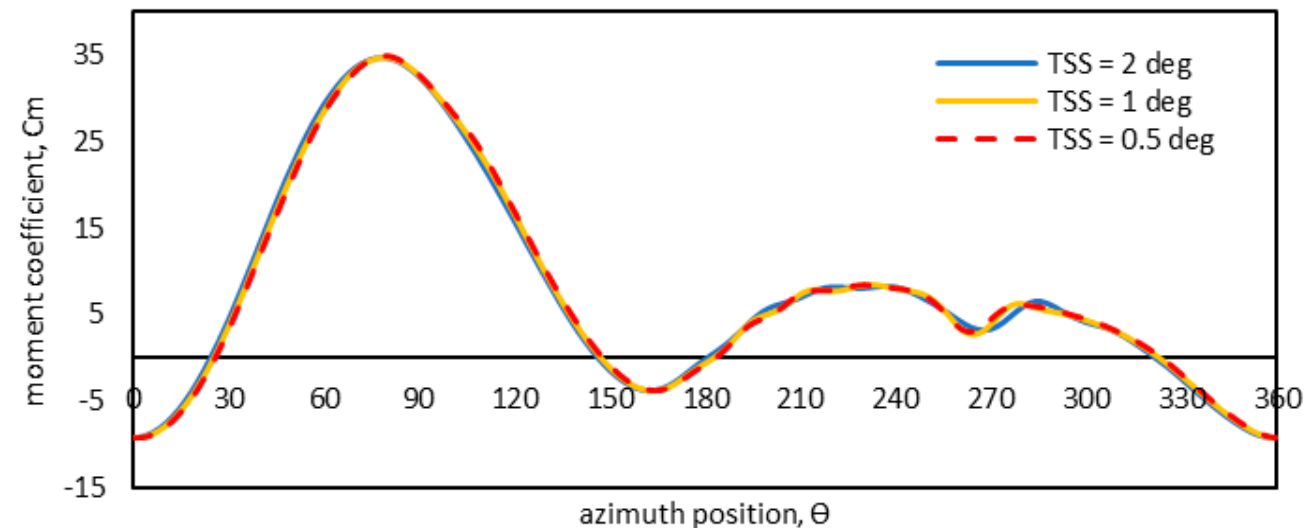

(b)

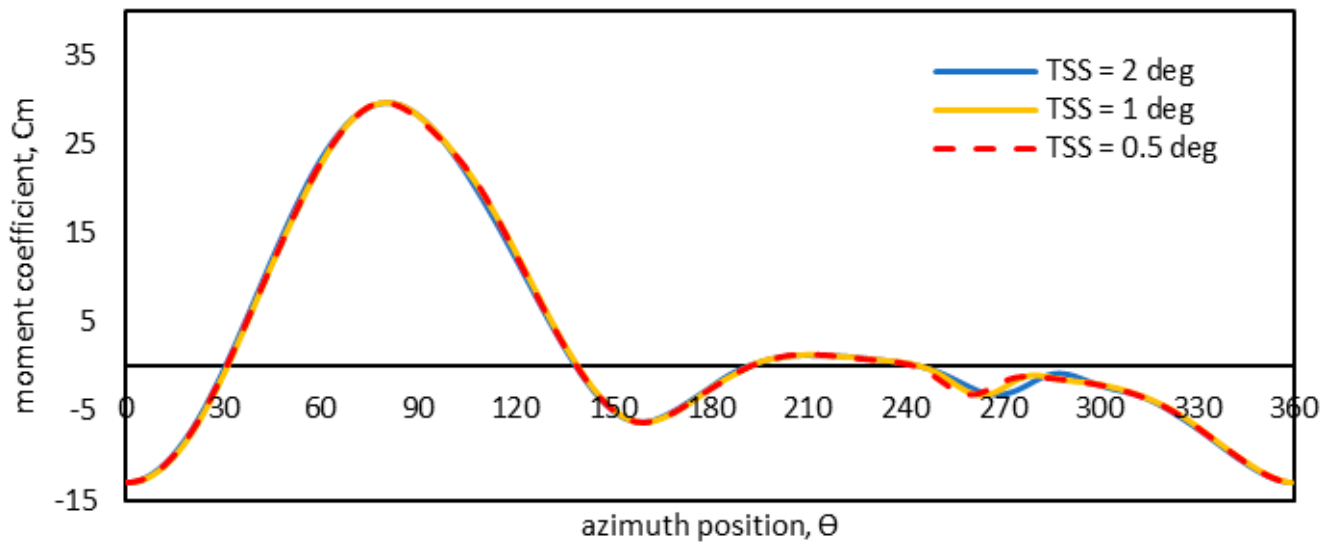

(c)

Figure 4. Time step size (TSS) study results on moment coefficient values for (a) $\lambda=3,(\mathbf{b}) \lambda=4$ and (c) $\lambda=5$.

A full tip speed ratio (TSR) sweep was investigated and the Cp curve is shown in Figure 6. The highest coefficient of performance, $C p$, was found to be at $\lambda=4$ with a value of 0.2758 , consistent with published literature where the maximum coefficient of performance for a Darrieus vertical axis wind turbine is at the tip speed ratio of 4 . For this reason, the tip speed ratio of 4 was chosen for subsequent simulations. 


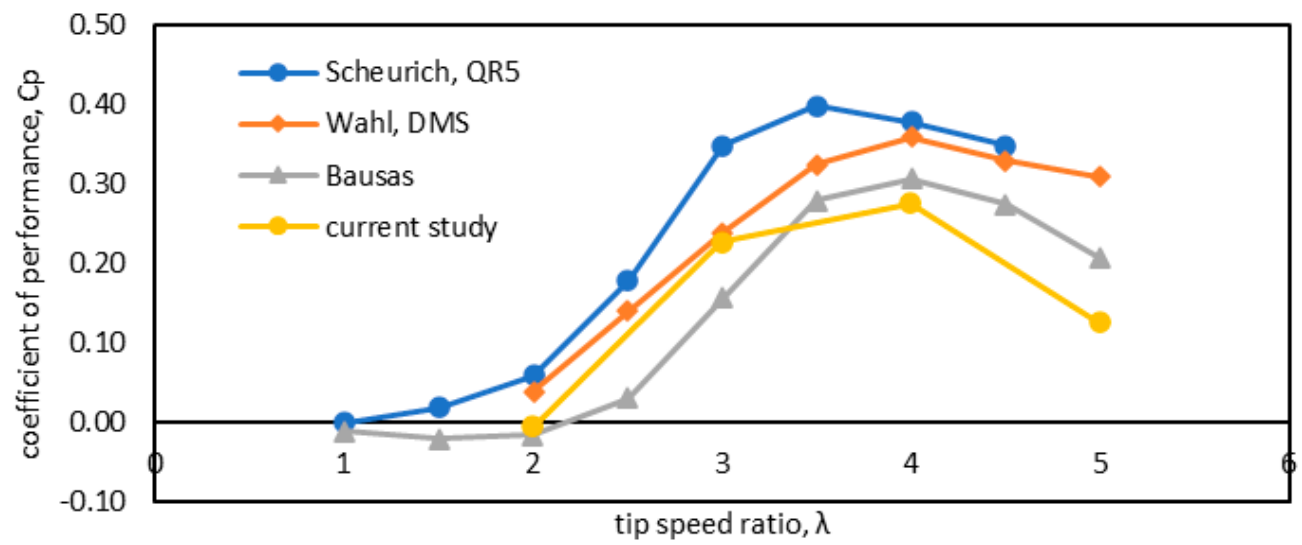

Figure 5. Simulation results superimposed with the results of previously published studies (adapted from [35]).

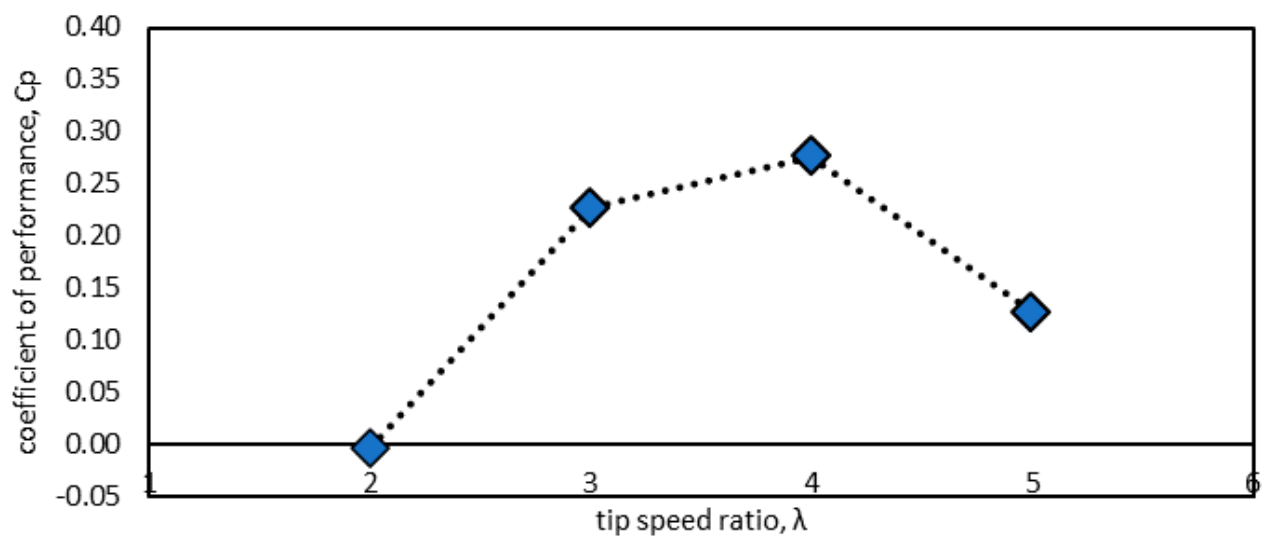

Figure 6. Cp curve of $\lambda=2,3,4$ and 5 at $2^{\circ}$ temporal resolution.

\subsection{Node Density Study}

The number of nodes comprising the shape of the airfoil also affects the result of the CFD simulation. Because the meshing software inflates the nodes from the airfoil toward the boundary of the domain, an excessive number of nodes on the airfoil may result in unnecessary demand for CPU memory and longer simulation times due to the resulting large number of cells. Meanwhile, low node density might lead to unreliable data.

To establish grid independence, three different meshes were developed: fine mesh, medium mesh and coarse mesh. All three meshes were simulated using the k- $\omega$ SST as the turbulence model. The computer used was an 8 -core processor at $4.20 \mathrm{GHz}$ clock speed and with $32 \mathrm{~GB}$ of random access memory.

The resulting computed $\mathrm{Cp}$ (Table 1) and torque ripples of the different node densities are almost identical (Figure 7) and the difference among the three meshes is almost negligible. To reduce the computational time without significant deterioration of the results, the medium mesh of 420 foil surface node resolution was considered the best candidate.

Table 1. Summary of the computed Cp for different node densities.

\begin{tabular}{cccc}
\hline Resolution & Coarse Mesh & Medium Mesh & Fine Mesh \\
\hline Number of Nodes on the Airfoil & 216 & 420 & 830 \\
Simulation Time & $3.70 \mathrm{~h}$ & $4.80 \mathrm{~h}$ & $7.05 \mathrm{~h}$ \\
Computed Cp & 0.2880 & 0.2758 & 0.2856 \\
\hline
\end{tabular}




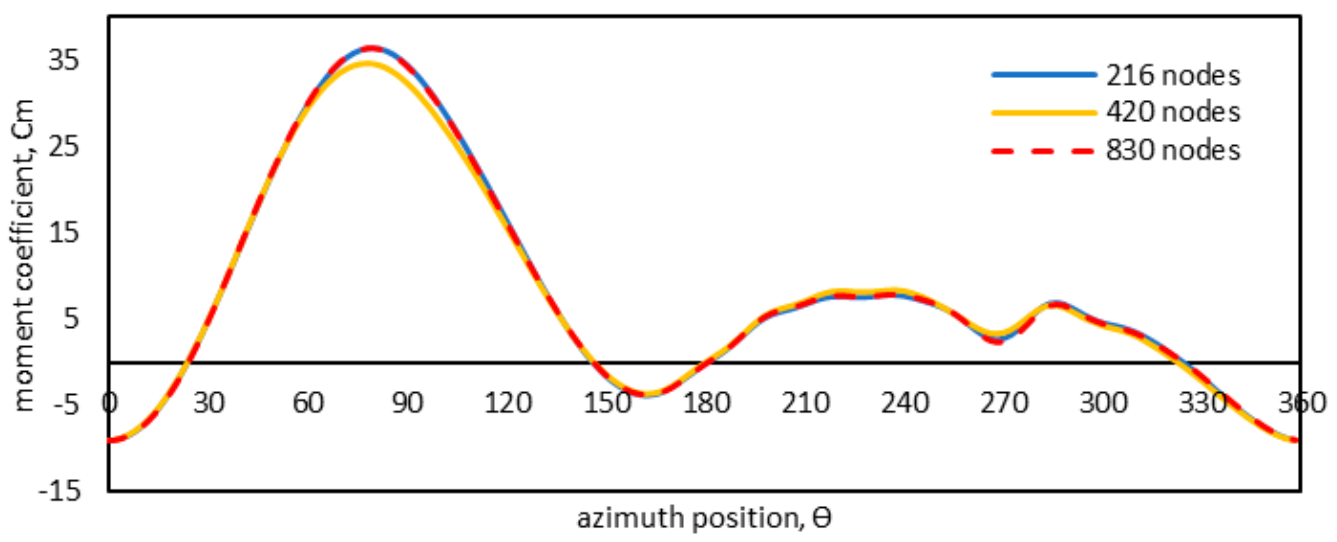

Figure 7. Torque plots for the coarse, medium and fine mesh.

\subsection{Validation Study}

There were no experimental data available for the node density study described in Section 2.5, hence, the authors had no means to compare the results against actual field values. Experimental data based on the study of Nguyen et al. [36] are available in the literature and were used to validate the model developed in Section 2.5. The same turbulence model, CFD settings and airfoil nodes were used for this validation study as with the model in Section 2.5, except for the turbulence intensity at the inlet, which is set to $5 \%$ and is the same value as in the experimental data.

The turbine performance was based on the data collected by Kjellin et al. for a 12-kW, 3-bladed Darrieus VAWT installed in Uppsala University, Sweden [37], and was interpreted by Nguyen et al. The blade profile of the turbine was modeled with varying airfoil nodes equal to 216, 420 and 830 nodes. As one can observe, there is not much variation in the moment coefficient across the azimuth positions for the studied airfoil node densities. The authors concluded that the choice of the number of nodes in the airfoil does not affect the results of the simulation, shown in Figure 8. The authors adopted 420 airfoil nodes for subsequent studies.

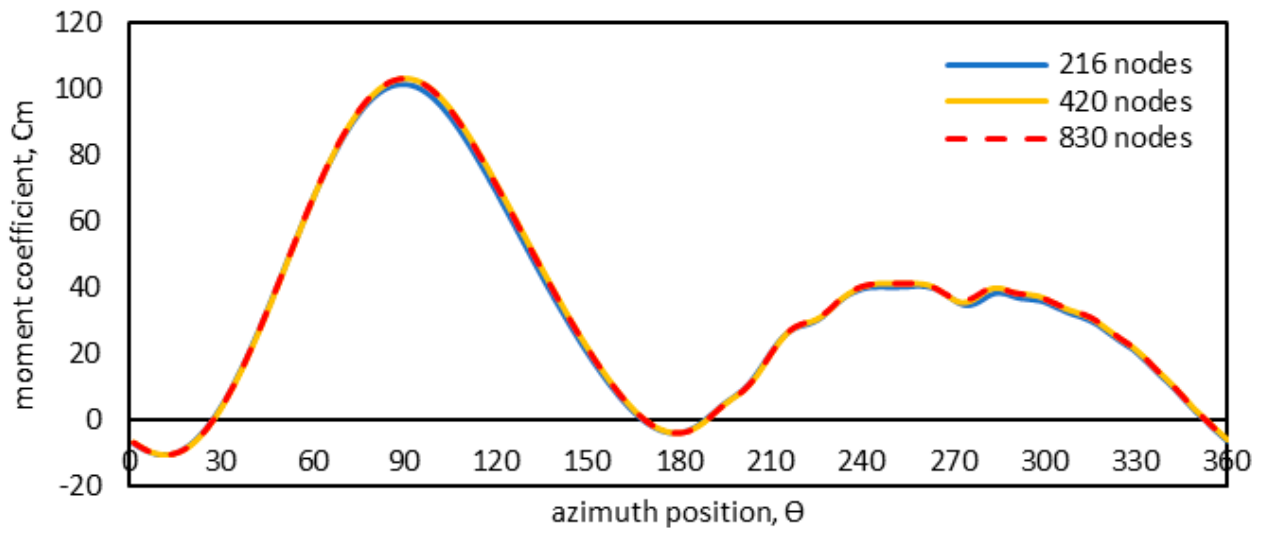

Figure 8. Node density study for the validation case.

To validate the model, the CFD results are compared with the experimental data from the study of Nguyen et al. (Figure 9). It can be observed that the curve of the predicted normal force on the airfoil generally follows the curve obtained from the experimental setup, with slight overprediction in the $60^{\circ}-120^{\circ}$ azimuth. Further, a similar trend between the experiment and the CFD simulation result on the time step size study is seen in Figure 10 with very little difference in predicted normal force between the time step sizes studied. These results show that the model adopted for the $5 \mathrm{~kW}$ rotor scale is appropriate and acceptable. 


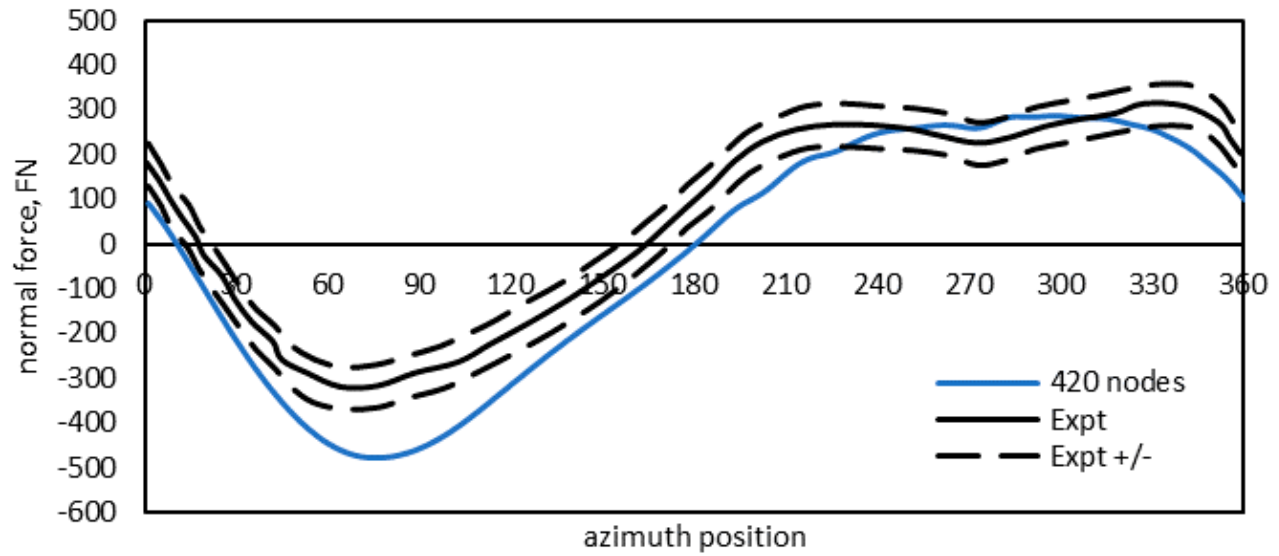

Figure 9. Airfoil normal force comparison between experimental data and CFD simulation across different azimuth positions.

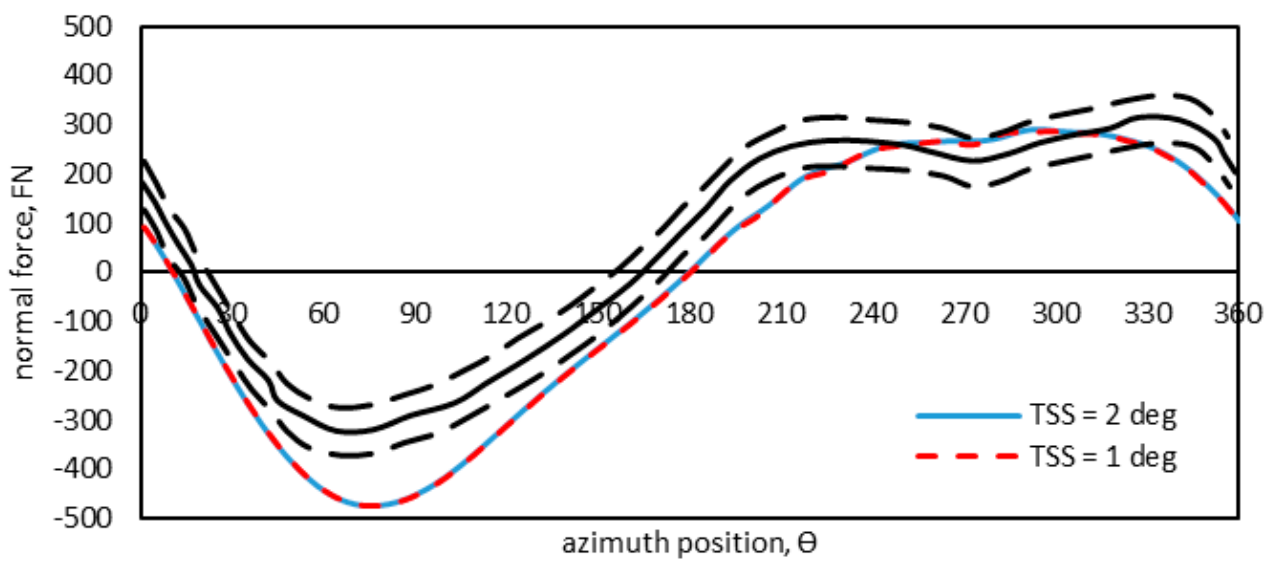

Figure 10. Airfoil normal force comparison between experimental data at time step sizes of $1^{\circ}$ and $2^{\circ}$ equivalent rotation.

\subsection{Simulation Phases}

The preliminary phase of the study involves the investigation of the appropriate time step size for the simulation, the number of nodes necessary for the airfoil shape, balancing the elements of computational time and accuracy of the simulation, and the determination of the tip speed ratio to be used based on the maximum $C p$ value and trend consistency based on previous related studies.

The next phase of the study is to investigate the influence of clustering at different turbine spacing distances. Simulations were performed at four different turbine spacing distances equivalent to twelve, eight, four and two rotor diameters angled at $60^{\circ}$ to each other $\left(120^{\circ}\right.$ oblique angle based on convention used in this study, Figure 11). The configuration was composed of three turbines: left turbine, center turbine and the right turbine. The center turbine was designated as the apex (for a pyramid arrangement) or base (for an inverse-pyramid arrangement) of the configuration.

After determining the optimal turbine spacing, the turbines were then simulated at varying oblique angles to investigate the effect of variation in angles on the trend of the performance of individual turbines and turbine clusters. Lastly, combinations of different turbine rotations were simulated to explore the effect of the sensitivity of turbine rotation directions on the resulting coefficient of the performance of the cluster.

All performed simulations were subjected to a constant wind velocity of $5.0 \mathrm{~m} / \mathrm{s}$ coming into the inlet section of the CFD domain. The same set of mesh settings, time step value, turbulence model, convergence criteria and tip speed ratio were used for all simulated cases. 


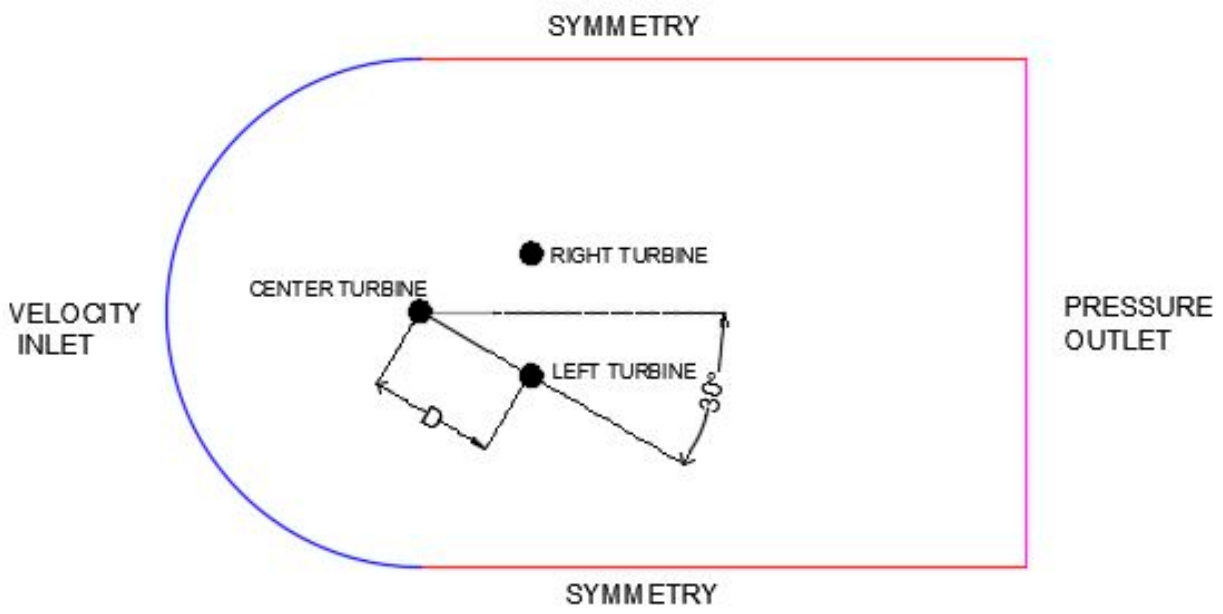

Figure 11. The CFD domain for turbine distance study.

\section{Results}

\subsection{Varying Turbine Distance Spacing}

Clusters of three turbines with turbine spacing equivalent to twelve, eight, four and two rotor diameters at an oblique angle equal to $120^{\circ}$ were simulated, and the calculated coefficient of performance based on the output file from the CFD simulation can be found in Tables 2-5. The resulting coefficients of performance of each turbine cluster arrangement were compared to the $\mathrm{Cp}$ of the isolated turbine. Figure 12 shows a plot of the individual computed Cps of all rotors for all distance cases investigated.

Table 2. Simulation results at 12 turbine diameter spacing.

\begin{tabular}{|c|c|c|c|c|}
\hline & $\begin{array}{l}\text { Isolated } \\
\text { Turbine }\end{array}$ & $\begin{array}{l}\text { Center } \\
\text { Turbine }\end{array}$ & $\begin{array}{c}\text { Left } \\
\text { Turbine }\end{array}$ & $\begin{array}{c}\text { Right } \\
\text { Turbine }\end{array}$ \\
\hline Power coefficient, $\mathrm{Cp}$ & 0.2758 & 0.2754 & 0.2811 & 0.2935 \\
\hline Increase in Cp of individual turbine vs. isolated rotor & & $-0.14 \%$ & $1.90 \%$ & $2.29 \%$ \\
\hline Average $\mathrm{Cp}$ of the cluster & \multicolumn{4}{|c|}{0.2796} \\
\hline Overall increase in $\mathrm{Cp}$ of the cluster vs. isolated rotor & \multicolumn{4}{|c|}{$+1.35 \%$} \\
\hline
\end{tabular}

Table 3. Simulation results at 8 turbine diameter spacing.

\begin{tabular}{ccccc}
\hline & $\begin{array}{c}\text { Isolated } \\
\text { Turbine }\end{array}$ & $\begin{array}{c}\text { Center } \\
\text { Turbine }\end{array}$ & $\begin{array}{c}\text { Left } \\
\text { Turbine }\end{array}$ & $\begin{array}{c}\text { Right } \\
\text { Turbine }\end{array}$ \\
\hline $\begin{array}{c}\text { Power coefficient, Cp } \\
\text { Tncrease in Cp of individual turbine vs. isolated rotor }\end{array}$ & 0.2758 & 0.2774 & 0.2903 & 0.2866 \\
Average Cp of the cluster & $0.56 \%$ & $5.24 \%$ & $3.92 \%$ \\
Overall increase in Cp of the cluster vs. isolated rotor & & 0.2848 & \\
\hline
\end{tabular}

Table 4. Simulation results at 4 turbine diameter spacing.

\begin{tabular}{|c|c|c|c|c|}
\hline & $\begin{array}{l}\text { Isolated } \\
\text { Turbine }\end{array}$ & $\begin{array}{l}\text { Center } \\
\text { Turbine }\end{array}$ & $\begin{array}{c}\text { Left } \\
\text { Turbine }\end{array}$ & $\begin{array}{c}\text { Right } \\
\text { Turbine }\end{array}$ \\
\hline Power coefficient, $\mathrm{Cp}$ & 0.2758 & 0.2790 & 0.2980 & 0.2949 \\
\hline Increase in Cp of individual turbine vs. isolated rotor & & $1.15 \%$ & $8.03 \%$ & $6.91 \%$ \\
\hline Average $\mathrm{Cp}$ of the cluster & \multicolumn{4}{|c|}{0.2906} \\
\hline Overall increase in $\mathrm{Cp}$ of the cluster vs. isolated rotor & \multicolumn{4}{|c|}{$+5.37 \%$} \\
\hline
\end{tabular}


Table 5. Simulation results at 2 turbine diameter spacing.

\begin{tabular}{|c|c|c|c|c|}
\hline & $\begin{array}{l}\text { Isolated } \\
\text { Turbine }\end{array}$ & $\begin{array}{l}\text { Center } \\
\text { Turbine }\end{array}$ & $\begin{array}{c}\text { Left } \\
\text { Turbine }\end{array}$ & $\begin{array}{c}\text { Right } \\
\text { Turbine }\end{array}$ \\
\hline Power coefficient, $\mathrm{Cp}$ & 0.2758 & 0.2708 & 0.3147 & 0.3086 \\
\hline Increase in $\mathrm{Cp}$ of individual turbine vs. isolated rotor & & $-1.82 \%$ & $14.09 \%$ & $11.89 \%$ \\
\hline Average $\mathrm{Cp}$ of the cluster & \multicolumn{4}{|c|}{0.2980} \\
\hline Overall increase in $\mathrm{Cp}$ of the cluster vs. isolated rotor & \multicolumn{4}{|c|}{$+8.06 \%$} \\
\hline
\end{tabular}

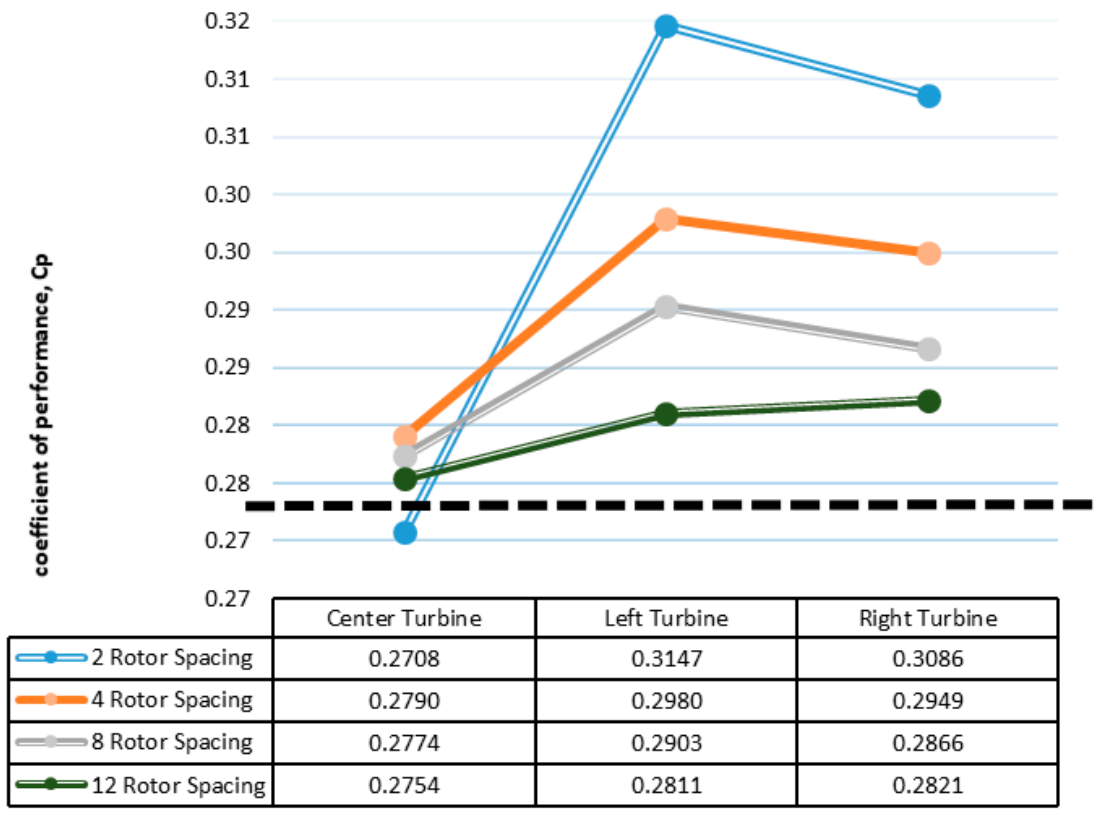

Figure 12. Summary of computed $\mathrm{Cp}$ at different turbine spacing distances. Note: black dashed line represents the $\mathrm{Cp}$ of the single turbine.

Significant improvement was observed for the cluster containing turbines with two rotor diameter spacing, which is the arrangement with the turbines closest to each other. The synergistic effect accounts for an improvement of $8.06 \%$ while the individual turbine performances were also seen to have increased significantly, at $14.09 \%$ and $11.89 \%$ for the left and right turbine, respectively. The performance of the center turbine (the upwind turbine) dropped slightly by $1.82 \%$. The left turbine exhibits the largest torque coefficient and, consequently, the highest performance compared to the right and center turbines. Wind velocity values around each turbine are mapped in Figure 13 to further explain the increased performance of the cluster. It can be seen that the two turbines flanking the center turbines exhibited higher wind velocities compared to the central turbine.

The C $\mathrm{p}$ values described in Tables $2-5$ were obtained from the simulation of the 18th rotation of the turbine clusters. To make sure that the results indeed converged, the last three rotations (i.e., 16th, 17th and 18th rotations) were compared. The differences in the results of the last three rotations are very close, with the variances ranging from $0.23 \%$ to a maximum of $1.81 \%$ and add to the fact that the residuals are very low, hence the results are deemed converged.

From Figure 13, the wind velocity profile in front of the turbines shows faster wind speed in front of the turbines located at the flank compared to the central turbine. Values of $4.70 \mathrm{~m} / \mathrm{s}$ to $4.90 \mathrm{~m} / \mathrm{s}$ can be found in front of the left and right turbines compared to about $4.50 \mathrm{~m} / \mathrm{s}$ to $4.70 \mathrm{~m} / \mathrm{s}$ for the center turbine. Meanwhile, when we shift our attention to the oblique area between the left and center turbines and right and center turbines, one can observe that further wind speed acceleration is happening in this area, where wind speed up to $5.50 \mathrm{~m} / \mathrm{s}$ can be found. The amplification on the incoming velocity, especially in the oblique region between the upwind and leeward turbines, can be described by the 
funnel effect, where an incoming wind stream finds its way by squeezing in between solid walls (i.e., the turbines), inducing the increase in velocity. The effect of the "funnel-like" restriction was greatest at an equivalent rotor spacing distance of two, then declines and finally goes away at a distance of 12 turbine diameters. At 12 turbine diameters, both the individual turbine and the average cluster performance have no appreciable difference from the performance of a single, isolated turbine. Hence, it can be established that clustered turbines are sufficiently far from the downwind and lateral boundaries, exerting no influence on the performance of the individual turbines.

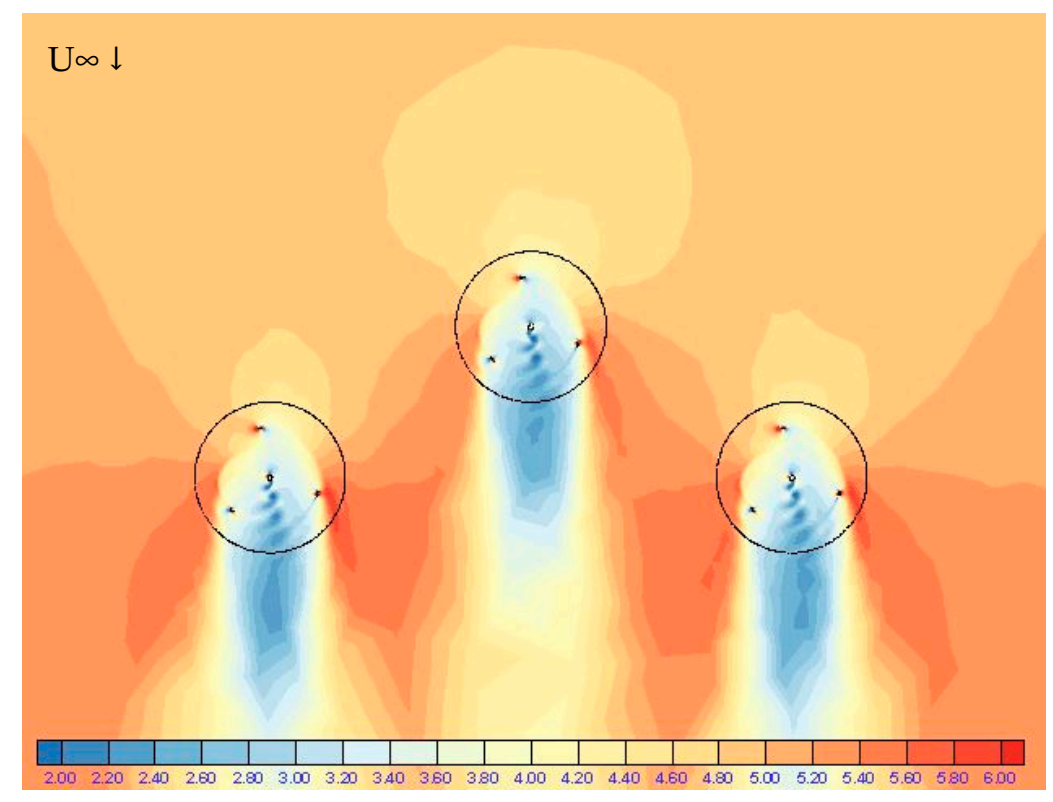

Figure 13. Velocity contours near the left, right and center turbine.

Velocity monitors were placed along a straight line and at a half rotor diameter distance windward of the turbines to numerically sample the wind velocities being received by the turbines. Compared to the isolated turbine which receives an average wind speed of $4.59 \mathrm{~m} / \mathrm{s}$, the center, left and right turbines accept velocities of $4.51 \mathrm{~m} / \mathrm{s}, 4.72 \mathrm{~m} / \mathrm{s}$ and $4.70 \mathrm{~m} / \mathrm{s}$, respectively. The sizable speed augmentation for the flank turbines and slight reduction in the center turbine correlate with the change in their computed performance compared to the isolated turbine. This is expected, as generated forces on the turbine blades due to higher local wind velocity will result in improved power extraction. The torque ripple of one blade for the three rotors is plotted in Figure 14. It can be seen that the generated torque by the blades of the center turbine is lower than the left and right turbines.

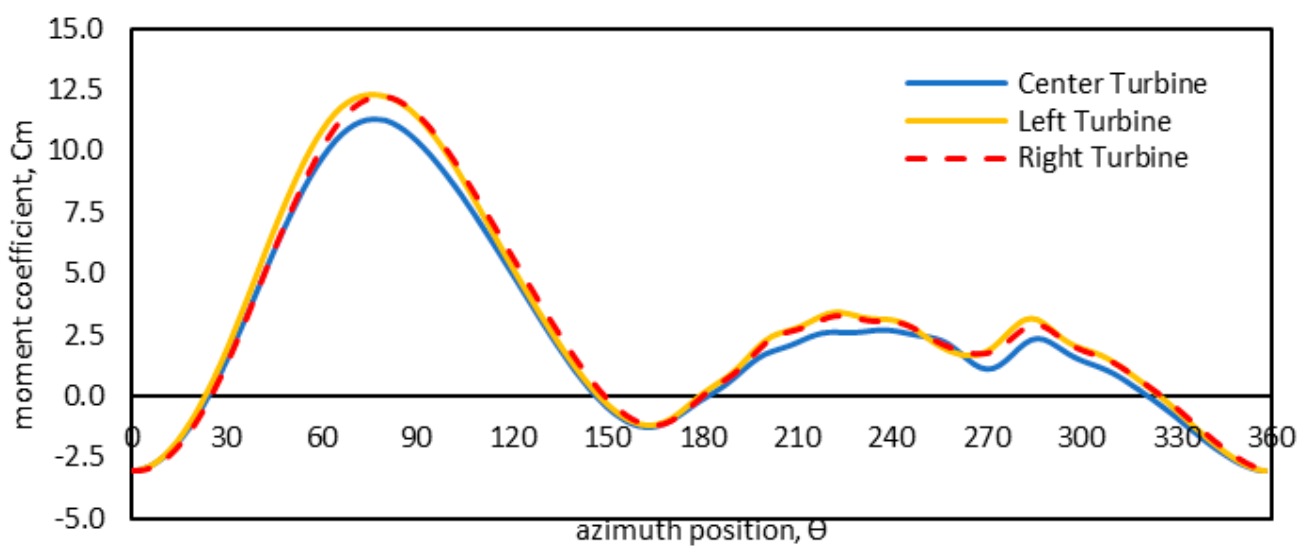

Figure 14. Torque ripple at 2 rotor distance configuration. 
One curious observation on the performance of the center turbine across different turbine spacing distances was that while its performance at a 12 equivalent rotor distance has negligible differences compared to the isolated turbine (which is expected, as established earlier), its performance declined at a two equivalent rotor distance. It can be noticed, though barely, in the plotted torque ripple for one rotor in Figure 15, that its torque values are consistently lower from $0^{\circ}$ to $240^{\circ}$ azimuth than that of 12,8 and 4 rotor distance cases. A visual representation of the velocities incoming to the center turbines confirms that a lower velocity region can be seen to be wider in front of the center turbine at a rotor spacing of two compared to other turbine spacing cases (Figure 16).

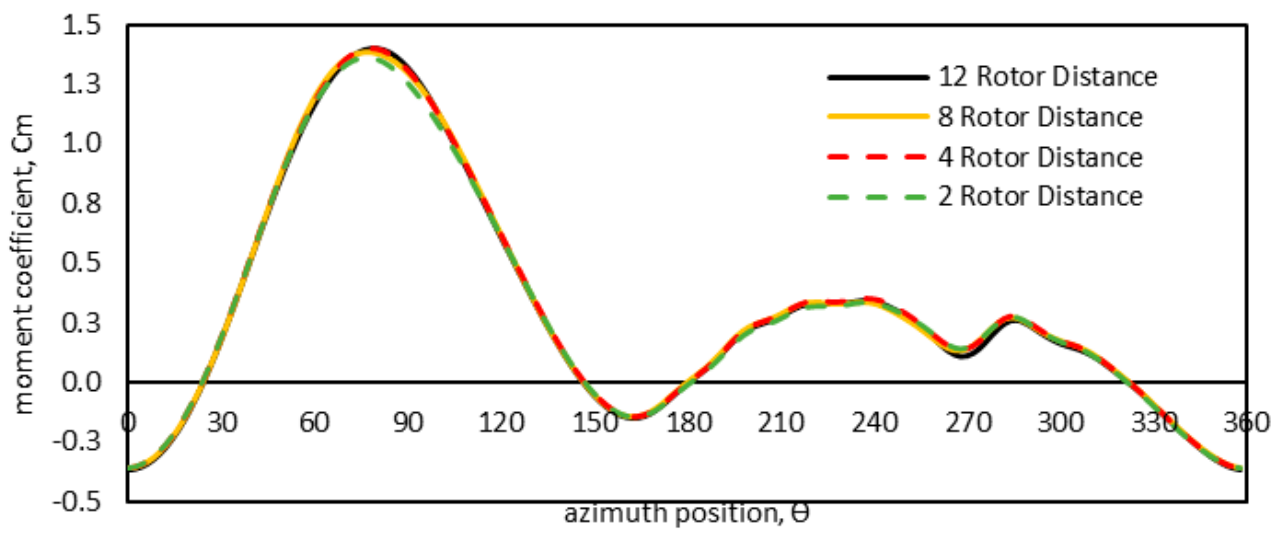

Figure 15. Torque ripple of center turbines at different turbine distances.

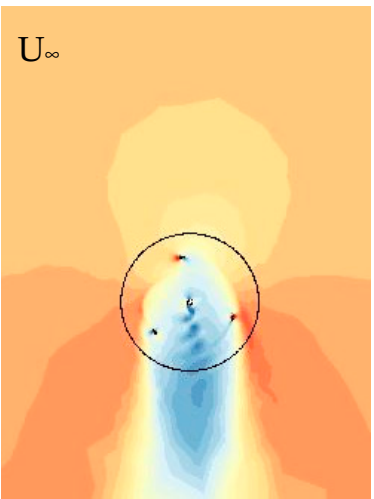

(a)

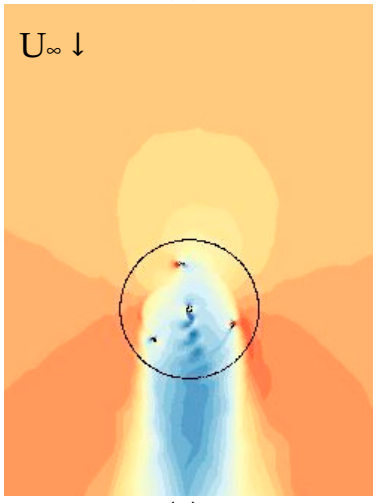

(c)

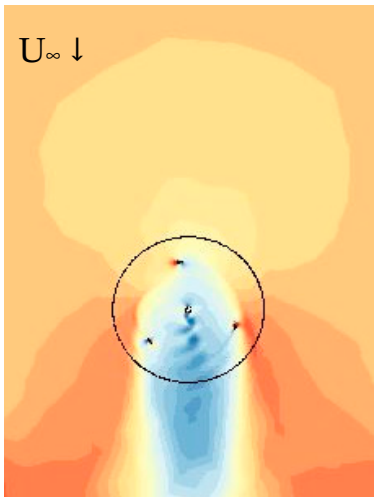

(b)

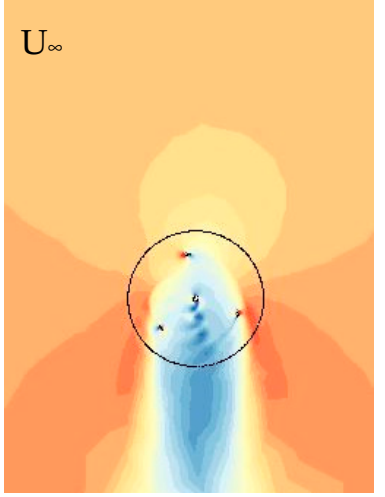

(d)

Figure 16. Velocity contours around center turbines of (a) 2 rotor distance, (b) 4 rotor distance, (c) 8 rotor distance and (d) 12 rotor distance.

Minimal change in both the individual rotors and the overall performance of the cluster with a 12 equivalent rotor diameter distance when compared to the isolated turbine 
case was observed. Hence, it can be deduced that the clustering effect and neighboring turbines' influence might not extend this far across the spacing. Individual turbines with a 12 equivalent rotor distance operate as if they are alone in the turbine farm.

\subsection{Varying Oblique Angles}

The conclusion from the previous simulation was that as the individual turbines were placed in close proximity to each other, an increase in the coefficient of performance can be achieved. Restriction and free-stream wind flows due to reduced turbine spacing induced relatively higher wind velocities in comparison to turbine clusters with broader spacing.

Aside from linear spacing, the oblique angle among the member turbines can also contribute to the compactness of the turbine farm array. To illustrate the idea, by changing the oblique angle from $30^{\circ}$ to $75^{\circ}$ at a fixed oblique distance of two rotor diameters, the distance in the $\mathrm{x}$-direction will be increased by 4.19 units, while the y-component will be decreased by 5.46. From the results of the distance study, it was deduced that varying turbine spacing affects the overall performance of the turbine cluster. Using the same logic, it is desired to understand if there will be significant variation in the $\mathrm{Cp}$ when the oblique angles are varied. Cases with varying oblique angles (convention defined in Figure 17) from $15^{\circ}$ to $165^{\circ}$ at $15^{\circ}$ angle increments were investigated. Simulated configurations from $15^{\circ}$ to $75^{\circ}$ resemble inverted pyramid formations, while configurations with angles from $105^{\circ}$ to $165^{\circ}$ look like a pyramid-shaped turbine cluster. The arrangement with $90^{\circ}$ oblique angles, on the other hand, is a linear configuration with the turbines laying in a straight line perpendicular to the source of the wind.

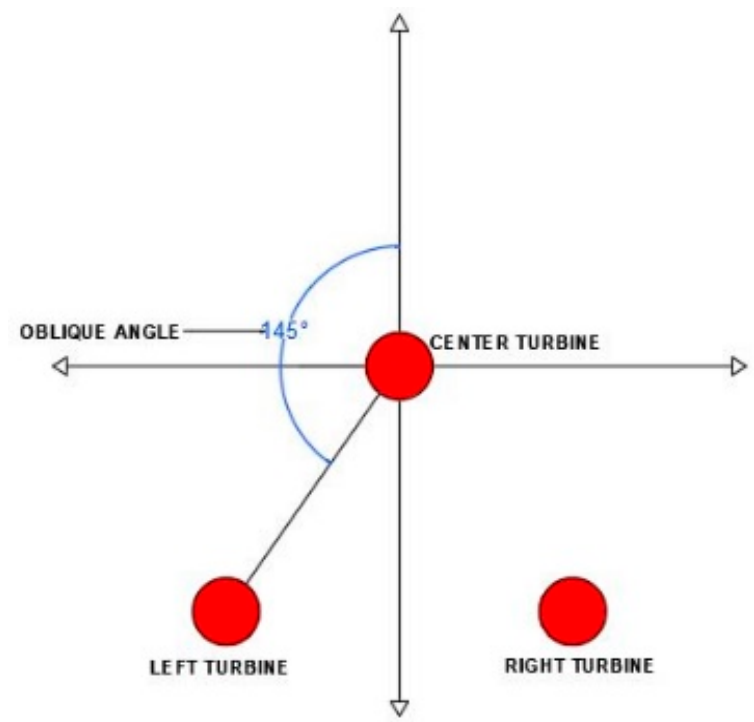

Figure 17. Oblique angle convention.

Both turbines flanking the center turbine (i.e., the left and right turbines) increased their coefficient of performance as the angle, with respect to streamwise direction, increased up to a $150^{\circ}$ oblique angle (Table 6). An exception was noted in the extreme case of $165^{\circ}$, wherein both turbines are almost behind the center turbine. This extreme case is evident when the velocity profile around the turbines is visualized, in which it is obvious that low velocity wind is being received by the downwind turbines (Figure 18k). The same is true with the complement configuration in the case of a $15^{\circ}$ oblique angle, wherein the upwind turbine receives low-velocity wind due to the wake induced by the very close presence of the left and right turbines (Figure 18a). The trend in the performance of the center turbine, on the other hand, is maximum at a $45^{\circ}$ oblique angle and then decreases as the oblique angle increases. 
Table 6. Coefficient of performance at different oblique angles.

\begin{tabular}{cccccc}
\hline $\begin{array}{c}\text { Oblique } \\
\text { Angle }\end{array}$ & $\begin{array}{c}\text { Left } \\
\text { Turbine }\end{array}$ & $\begin{array}{c}\text { Center } \\
\text { Turbine }\end{array}$ & $\begin{array}{c}\text { Right } \\
\text { Turbine }\end{array}$ & $\begin{array}{c}\text { Average } \\
\text { Cp }\end{array}$ & $\begin{array}{c}\text { Improvement Compared } \\
\text { to Single Turbine }\end{array}$ \\
\hline $15^{\circ}$ & 0.2733 & 0.2512 & 0.2710 & 0.2652 & $-3.86 \%$ \\
$30^{\circ}$ & 0.2726 & 0.3406 & 0.2712 & 0.2948 & $6.88 \%$ \\
$45^{\circ}$ & 0.2812 & 0.3424 & 0.2713 & 0.2983 & $8.14 \%$ \\
$60^{\circ}$ & 0.2882 & 0.3294 & 0.2808 & 0.2995 & $8.57 \%$ \\
$75^{\circ}$ & 0.2962 & 0.3217 & 0.2888 & 0.3022 & $9.57 \%$ \\
$90^{\circ}$ & 0.3041 & 0.3061 & 0.2982 & 0.3028 & $9.78 \%$ \\
$105^{\circ}$ & 0.3050 & 0.2870 & 0.3036 & 0.2986 & $8.24 \%$ \\
$120^{\circ}$ & 0.3147 & 0.2708 & 0.3086 & 0.2980 & $8.06 \%$ \\
$135^{\circ}$ & 0.3233 & 0.2535 & 0.3161 & 0.2976 & $7.90 \%$ \\
$150^{\circ}$ & 0.3275 & 0.2305 & 0.3240 & 0.2940 & $6.58 \%$ \\
$165^{\circ}$ & 0.2245 & 0.2138 & 0.1885 & 0.2090 & $-24.24 \%$ \\
\hline
\end{tabular}

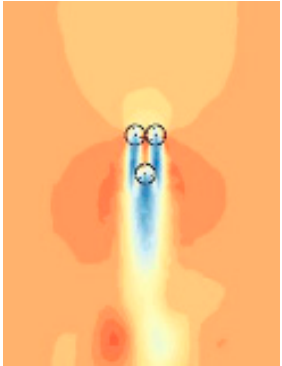

(a)

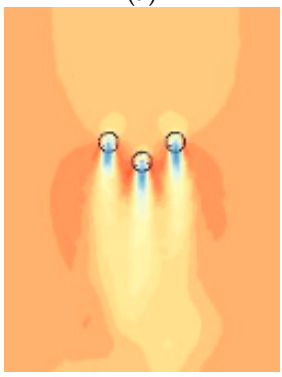

(d)

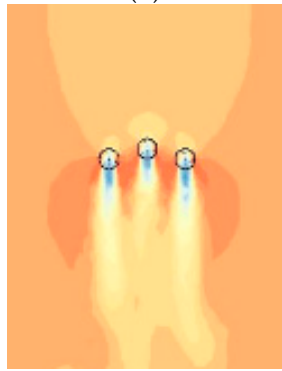

(g)

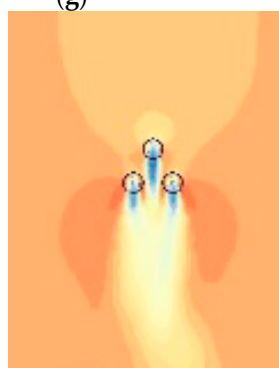

(j)

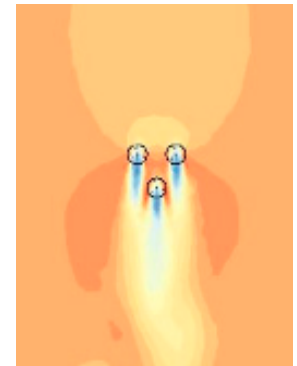

(b)

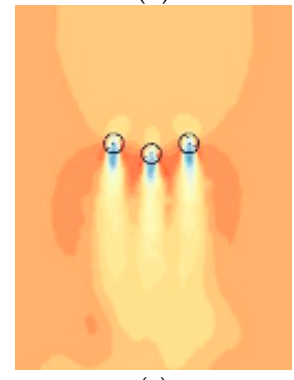

(e)

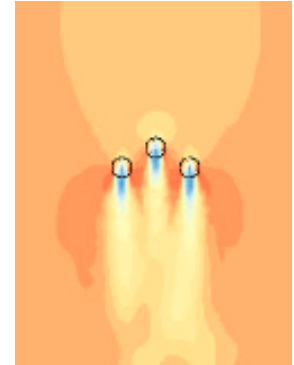

(h)

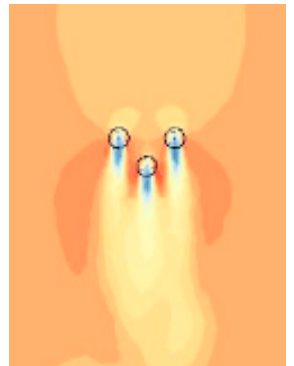

(c)

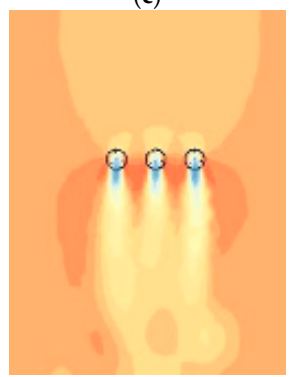

$(\mathbf{f})$

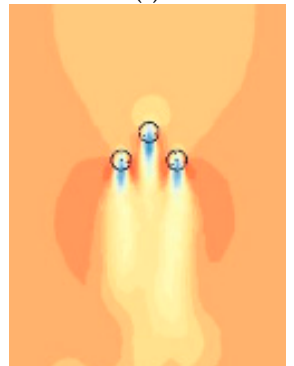

(i)

Figure 18. Contour plots of velocity magnitude within the domain for oblique angles of (a) $15^{\circ}$, (b) $30^{\circ}$, (c) $45^{\circ}$, (d) $60^{\circ}$, (e) $75^{\circ}$, (f) $90^{\circ}$, (g) $105^{\circ}$, (h) $120^{\circ}$, (i) $135^{\circ}$, (j) $150^{\circ}$ and (k) $165^{\circ}$. 
Although the greatest improvement experienced by the center turbine is at $45^{\circ}$, while the flanking turbines' maximum improvement was found to be at $150^{\circ}$, the maximum average improvement in the performance of the different cluster configurations was at $90^{\circ}$, which is when the turbines are in a collinear position and perpendicular to the source of the wind. A plot of the power coefficient versus the oblique angle for the individual turbines and the cluster performance can be found in Figure 19. Obviously, the cluster performance increases as oblique angle approaches a straight line (i.e., $90^{\circ}$ ) from either pyramid or inverted pyramid positions. This conclusion supports the previous findings of Zanforlin and Nichino, wherein they deduced that the performances of turbines arranged in staggered manner cannot surpass those of turbines arranged side by side [38].

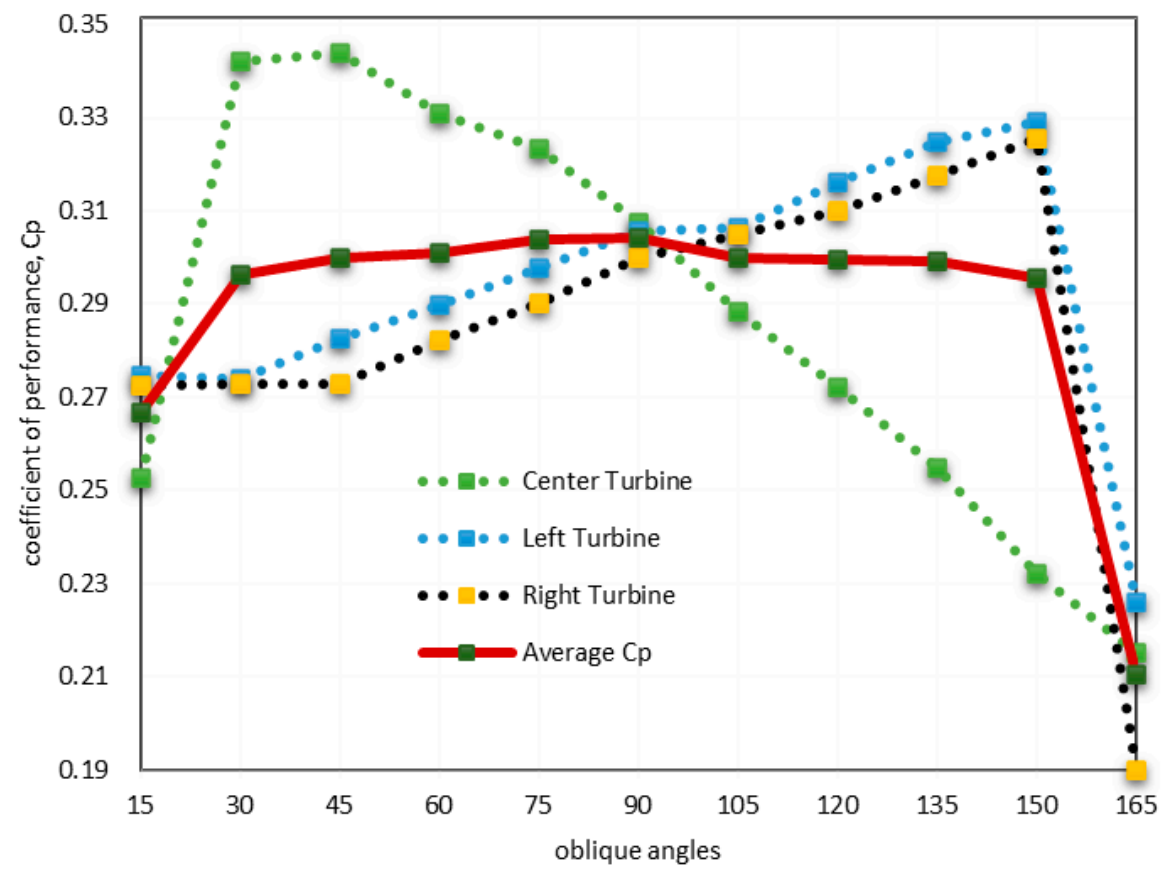

Figure 19. Trends in the power coefficient at different oblique angles.

Examining the case of a $15^{\circ}$ oblique angle, there was a significant reduction of wind velocity (illustrated by the long, blue contour) received by the leeward turbine due to the wake coming from the windward turbines (Figure 18a). Since the upwind turbines are almost directly in front of the downwind turbines, incoming wind velocity was blocked by the turbines in the front, thereby slowing the speed of the incoming wind. This is detrimental to the performance of the turbines and evidently resulted in the decline in the computed $\mathrm{Cp}$ for both the individual turbine and the cluster.

The same observation can be seen for the case with a $165^{\circ}$ oblique angle, but this time it is the wake of the center turbine that is being received by the left and right turbines, resulting in much lower coefficients of performance. Actually, the case with a $165^{\circ}$ oblique angle showed the lowest cluster performance among the studied cases. This result is logically reasonable since for the $15^{\circ}$ case, only one turbine is being negatively affected by the wake of the upwind turbines, but for the $165^{\circ}$ case, the two rear turbines were affected by the velocity reduction coming from the center turbine. Both of the cases mentioned above, where the angle separation between turbines was small, exhibit significant decreases in the overall performance compared to other cases and even to the singular turbine. The minimal angle separation makes the cluster clumped, inducing a blockage effect on the incoming wind, thereby reducing its velocity and consequently the performance of both the individual turbines as well as the turbine array.

For the pyramid configuration $\left(165^{\circ}\right.$ to $\left.90^{\circ}\right)$, it was observed that when the left and right turbines started to align with the center turbine, the low-velocity wind wake coming 
from the center turbine started to reduce its effect on the left and right turbines because of the angle separation. Hence, it is observed that the performance of these turbines improves, attaining the maximum coefficient of performance when the turbines are fully aligned in a straight line (Figure 18f). The torque ripple of the sum of turbines in one rotation with varying oblique angles is plotted in Figure 20. A slight but visible reduction in torque for an oblique angle of $15^{\circ}$ is noticeable. For the inverse-pyramid configuration, meanwhile, the increasing angle separation from $15^{\circ}$ to $90^{\circ}$ results in the reduction of the wake influence of the left and right turbines on the center turbine. Figure 21 shows the torque ripple and the obvious improvement when the angle goes from $15^{\circ}$ to $90^{\circ}$. Notice that the torque in the case of $90^{\circ}$ is consistently larger across all azimuth positions.

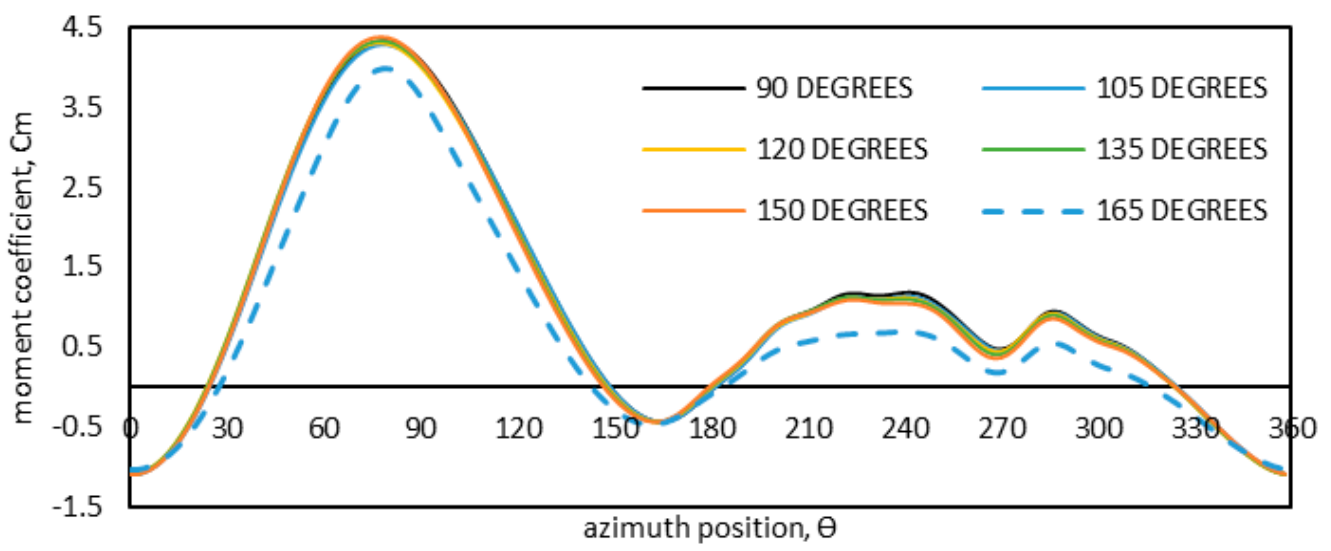

Figure 20. Torque ripple at various oblique angles $\left(90^{\circ}\right.$ to $\left.165^{\circ}\right)$.

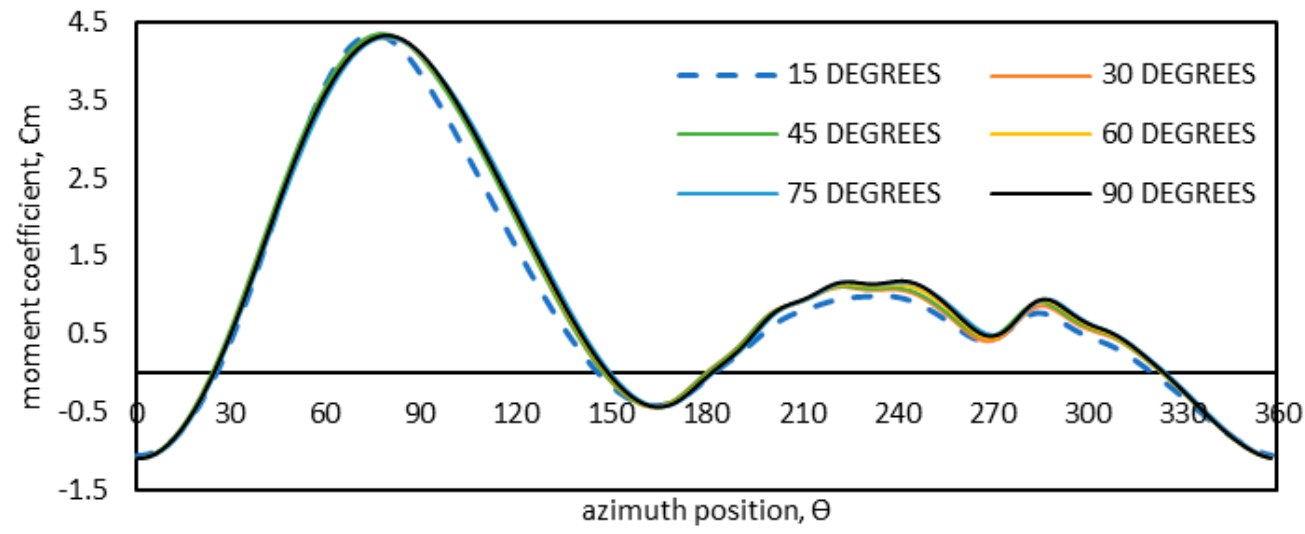

Figure 21. Torque ripple at various oblique angles $\left(15^{\circ}\right.$ to $\left.90^{\circ}\right)$.

\subsection{Varying Rotational Direction}

Dabiri et al. investigated the effect of counter-rotating VAWTs on the mechanics of airflow in between turbines. Their findings showed that counter-rotating turbines ensure that the airflow induced by the pair of turbines between them was oriented and flowing in the same direction, hence the production of wind shear, leading to turbulence and energy dissipation, will be reduced [11].

Experimental studies of Kinzel et al., meanwhile, utilized nine pairs of counter-rotating VAWTs and found that the distance where $95 \%$ of the wind velocity upwind was recovered was about 6D, much shorter than the 14D for HAWTs based on published literature [5,39]. Another study showed that counter-rotating configurations containing a pair of VAWTs placed side by side resulted in a favorable performance coefficient which was more than $10 \%$ compared to isolated turbines [40]. The study postulated that the cause of the improvement in the performance of the twin turbines was wake "re-energisation" and vortex shedding 
suppression, canceling the generated counter-rotating eddies due to the close proximity of the turbines.

To investigate the effect of the direction of turbine rotations, the authors examined the case of a turbine cluster with an internal angle of $90^{\circ}$ in different possible combinations of rotations for the individual turbines. Since there are three turbines per configuration, the number of different arrangements sensitive to the direction of rotations is eight. Therefore, an additional seven simulations were carried out to fully understand the effect of varying the direction of turbine rotations.

Table 7 summarizes the computed coefficient of performance in different rotational combinations of the individual turbines based on either clockwise rotation $(\mathrm{CW})$ or counterclockwise rotation (CCW). From the results of the simulations, it is interesting to observe that across the different combinations of rotations, the variation in the Cps is minimal, with the variation per pair ranging from $0.02 \%$ to $0.45 \%$. Further, the disparity among the individual turbines for each cluster is also practically undetectable.

Table 7. Power coefficient with varying rotational directions.

\begin{tabular}{cccccccc}
\hline \multicolumn{2}{c}{ Direction of Rotation } & \multicolumn{2}{c}{ Coefficient of Performance } & \multirow{2}{*}{ Average Cp } & \multirow{2}{*}{ Variation } \\
\cline { 1 - 5 } Left & Center & Right & Left & Center & Right & & \\
\cline { 1 - 5 } CW & CW & CCW & 0.3033 & 0.3072 & 0.3006 & 0.3037 & \multirow{2}{*}{$0.12 \%$} \\
CW & CCW & CCW & 0.3055 & 0.3057 & 0.2988 & 0.3033 & \\
CCW & CCW & CCW & 0.3061 & 0.3041 & 0.2982 & 0.3028 & $0.02 \%$ \\
CW & CW & CW & 0.3029 & 0.3045 & 0.3009 & 0.3027 & \\
CCW & CW & CW & 0.3016 & 0.3025 & 0.2996 & 0.3012 & $0.06 \%$ \\
CCW & CCW & CW & 0.3044 & 0.3016 & 0.2972 & 0.3011 & \\
CW & CCW & CW & 0.3043 & 0.3039 & 0.2985 & 0.3022 & $0.45 \%$ \\
CCW & CW & CCW & 0.3024 & 0.3031 & 0.2971 & 0.3009 & \\
\hline
\end{tabular}

\section{Conclusions}

Different cluster configurations composed of three turbines were simulated using CFD to find the effect of the turbine spacing, the compactness of the turbine cluster and varying turbine rotation combinations on the overall performance of the cluster, and were then compared to the performance of an isolated turbine. The case with the smallest turbine spacing, at two equivalent rotor diameters, was found out be significantly improved compared to the single turbine. Visual representations of velocities around turbines and velocity magnitude sampling in front of the turbines support the trend in the cluster performance.

Reduced the projected frontal area of a turbine cluster due to the proximity of the turbines induced a solid blockage, causing a reduction of incoming velocity received by the downwind turbines. Hence, the maximum overall coefficient of performance in the varying angle study was achieved in the case with an oblique angle of $90^{\circ}$, while minimum values were achieved at $15^{\circ}$ and $165^{\circ}$. The left and right turbines attained the greatest coefficient of performance at $150^{\circ}$, while at $45^{\circ}$, the center turbine's performance is at maximum.

Mirror image pairs of turbine cluster arrangements have no detectable variation in the overall performance coefficient. Likewise, the different possible rotational combinations investigated in this study yield an almost constant coefficient of performance. Hence, the resulting performance of a three-member turbine cluster arranged in a linear fashion in this study is insensitive to the direction of rotations of the individual turbines.

Author Contributions: Conceptualization, J.E.S. and L.A.M.D.; methodology, J.E.S. and L.A.M.D.; software, J.E.S. and L.A.M.D.; validation, J.E.S. and L.A.M.D.; formal analysis, J.E.S.; investigation, J.E.S.; resources, J.E.S.; writing-original draft preparation, J.E.S.; writing-review and editing, L.A.M.D.; visualization, J.E.S.; supervision, L.A.M.D.; funding acquisition, L.A.M.D. All authors have read and agreed to the published version of the manuscript. 
Funding: The authors thank the Department of Science and Technology Engineering Research and Development for Technology (DOST ERDT) for the funding of the APC.

Institutional Review Board Statement: Not applicable.

Informed Consent Statement: Not applicable.

Data Availability Statement: The data presented in this study are available on request from the corresponding author. The data are not publicly available due to constraints of an ongoing research work.

Conflicts of Interest: The authors declare no conflict of interest.

$\begin{array}{ll}\text { Abbreviations } \\ \text { CFD } & \begin{array}{l}\text { computational fluid dynamics } \\ \text { Cp }\end{array} \\ \text { coefficient of performance } \\ \text { HAWT } & \text { horizontal axis wind turbine } \\ \text { NACA } & \text { National Advisory Council on Aeronautics } \\ \text { RANS } & \text { Reynolds-averaged Navier-Stokes } \\ \text { SST } & \text { shear stress transport } \\ \text { VAWT } & \text { vertical axis wind turbine } \\ \text { y+ } & \text { non-dimensional wall distance } \\ \Delta t & \text { time step size } \\ \Lambda & \text { tip speed ratio } \\ \Omega & \text { rotational velocity } \\ \Sigma & \text { solidity }\end{array}$

\section{References}

1. Sorensen, B.; Sorensen, B. Renewable energy: Physics, engineering, environmental impacts, economics and planning. Organo Met. 2004, 30, 2051-2058.

2. Hau, E. Wind Turbines: Fundamentals, Technologies, Application, Economics; Springer Science and Business Media: Berlin/Heidelberg, Germany, 2013.

3. Zheng, H.-D.; Zheng, X.; Zhao, S. Arrangement of clustered straight-bladed wind turbines. Energy 2020, 200, 117563. [CrossRef]

4. Tang, H.; Lam, K.-M.; Shum, K.-M.; Li, Y. Wake Effect of a Horizontal Axis Wind Turbine on the Performance of a Downstream Turbine. Energies 2019, 12, 2395. [CrossRef]

5. Kinzel, M.; Mulligan, Q.; Dabiri, J.O. Energy exchange in an array of vertical-axis wind turbines. J. Turbul. 2012, 13, N38. [CrossRef]

6. Brownstein, I.D.; Wei, N.J.; Dabiri, J.O. Aerodynamically Interacting Vertical-Axis Wind Turbines: Performance Enhancement and Three-Dimensional Flow. Energies 2019, 12, 2724. [CrossRef]

7. Bremseth, J.; Duraisamy, K. Computational analysis of vertical axis wind turbine arrays. Theor. Comput. Fluid Dyn. 2016, 30, 387-401. [CrossRef]

8. Molina, A.C.; de Troyer, T.; Massai, T.; Vergaerde, A.; Runacres, M.C.; Bartoli, G. Effect of turbulence on the performance of VAWTs: An experimental study in two different wind tunnels. J. Wind. Eng. Ind. Aerodyn. 2019, 193, 103969. [CrossRef]

9. Vergaerde, A.; Troyer, T.; Muggiasca, S.; Bayati, I.; Belloli, M.; Klucweska-Bordier, J.; Parneix, N.; Silvert, F.; Runacres, M. Experimental characterization of the wake behind paired vertical-axis wind turbines. J. Wind Ind. Aerodyn. 2020, $206,104353$. [CrossRef]

10. Shaheen, M.; Abdallah, S. Development of efficient vertical axis wind turbine clustered farms. Renew. Sustain. Energy Rev. 2016, 63, 237-244. [CrossRef]

11. Dabiri, J. Potential order-of-magnitude enhancement of wind farm power density via counter-rotating vertical-axis wind tur-bine arrays. J. Renew. Sustain. Energy 2011, 3, 043104. [CrossRef]

12. Zhang, B.; Song, B.; Mao, Z.; Tian, W. A novel wake energy reuse method to optimize the layout for Savonius-type VAWT. Energy 2017, 121, 341-355. [CrossRef]

13. Iliev, S. Array Losses and Array Benefits: The Atmospheric Blockage Effect at Offshore Wind Parks. Master's Thesis, Delft University of Technology, Delft, The Netherlands, 2014.

14. Barber, S.; Nordborg, H. Comparison of simulations and wind tunnel measurements for the improvement of design tools for Vertical Axis Wind Turbines. In Proceedings of the Journal of Physics: Conference Series, WindEurope conference 2018 within the Global Wind Summit, Hamburg, Germany, 25-28 September 2018; IOP Publishing: Bristol, UK, 2018; Volume 1102, p. 012002.

15. Shamsoddin, S.; Porte-Angel, F. Large Eddy Simulation of Vertical Axis Wind Turbine Wakes. Energies 2014, 7, 890-912. [CrossRef]

16. Peng, J. Effects of Aerodynamic Interactions of Closely-Placed Vertical Axis Wind Turbine Pairs. Energies 2018, 11, 2842. [CrossRef] 
17. Bangga, G.; Dessoky, A.; Wu, Z.; Rogowski, K.; Hansen, M.O. Accuracy and consistency of CFD and engineering models for simulating vertical axis wind turbine loads. Energy 2020, 206, 118087. [CrossRef]

18. Wang, W.-C.; Wang, J.-J.; Chong, W.T. The effects of unsteady wind on the performances of a newly developed cross-axis wind turbine: A wind tunnel study. Renew. Energy 2019, 131, 644-659. [CrossRef]

19. Wekesa, D.W.; Wang, C.; Wei, Y.; Kamau, J.N.; Danao, L.A.M. A numerical analysis of unsteady inflow wind for site specific vertical axis wind turbine: A case study for Marsabit and Garissa in Kenya. Renew. Energy 2015, 76, 648-661. [CrossRef]

20. Castelli, M.R.; Englaro, A.; Benini, E. The Darrieus wind turbine: Proposal for a new performance prediction model based on CFD. Energy 2011, 36, 4919-4934. [CrossRef]

21. Moussa, M.O. Experimental and numerical performances analysis of a small three blades wind turbine. Energy 2020, 203, 117807. [CrossRef]

22. He, J.; Jin, X.; Xie, S.; Cao, L.; Wang, Y.; Lin, Y.; Wang, N. CFD modeling of varying complexity for aerodynamic analysis of H-vertical axis wind turbines. Renew. Energy 2020, 145, 2658-2670. [CrossRef]

23. Jin, G.; Zong, Z.; Jiang, Y.; Zou, L. Aerodynamic analysis of side-by-side placed twin vertical-axis wind turbines. Ocean. Eng. 2020, 209, 107296. [CrossRef]

24. Posa, A. Wake characterization of coupled configurations of vertical axis wind turbines using Large Eddy Simulation. Int. J. Heat Fluid Flow 2019, 75, 27-43. [CrossRef]

25. Peng, H.; Han, Z.; Liu, H.; Lin, K.; Lam, H. Assessment and optimization of the power performance of twin vertical axis wind turbines via numerical simulations. Renew. Energy 2020, 147, 43-54. [CrossRef]

26. Ahmadi-Baloutaki, M.; Carriveau, R.; Ting, D.S.-K. A wind tunnel study on the aerodynamic interaction of vertical axis wind turbines in array configurations. Renew. Energy 2016, 96, 904-913. [CrossRef]

27. Ferreira, C.J.S.; Bijl, H.; van Bussel, G.; van Kuik, G. Simulating Dynamic Stall in a 2D VAWT: Modeling strategy, verification and validation with Particle Image Velocimetry data. J. Phy. Conf. Ser. 2007, 75, 012023. [CrossRef]

28. Gridgen User Manual Version 15, Software Documentation; Pointwise Inc.: Fort Worth, TX, USA, 2002.

29. Lanzafame, R.; Mauro, S.; Messina, M. Wind turbine CFD modeling using a correlation-based transitional model. Renew. Energy 2013, 52, 31-39. [CrossRef]

30. Lanzafame, R.; Mauro, S.; Messina, M. 2D CFD Modeling of H-Darrieus Wind Turbines Using a Transition Turbulence Model. Energy Procedia 2014, 45, 131-140. [CrossRef]

31. Menter, F.; Kuntz, M.; Langtry, R. Ten years of industrial experience with the SST turbulence model. Flow Turbul. Combust. 2006, 77, 277-303. [CrossRef]

32. Chowdhury, A.; Akimoto, H.; Hara, Y. Comparative CFD analysis of Vertical Axis Wind Turbine in upright and tilted configuration. Renew. Energy 2016, 85, 327-337. [CrossRef]

33. Bianchini, A.; Balduzzi, F.; Ferrara, G.; Ferrari, L.; Persico, G.; Dossena, V.; Battisti, L. Detailed analysis of the wake structure of a straight-bladed H-Darrieus wind turbine by means of wind tunnel experiments and Computational Fluid Dynamics simula-tions. J. Eng. Gas Turbines Power 2018, 140, 032604. [CrossRef]

34. Franchina, N.; Persico, G.; Savini, M. 2D-3D Computations of a Vertical Axis Wind Turbine Flow Field: Modeling Issues and Physical Interpretations. Renew. Energy 2019, 136, 1170-1189. [CrossRef]

35. Bausas, M.D.; Danao, L.A.M. The aerodynamics of a camber-bladed vertical axis wind turbine in unsteady wind. Energy 2015, 93, 1155-1164. [CrossRef]

36. Nguyen, M.; Balduzzi, F.; Bianchini, A.; Ferrara, G.; Goude, A. Evaluation of the unsteady aerodynamic forces acting on a vertical-xis turbine by means of numerical simulations and open site experiments. J. Wind Eng. Ind. Aerodyn. 2020, $198,104093$. [CrossRef]

37. Kjellin, J.; Bülow, F.; Eriksson, S.; Deglaire, P.; Leijon, M.; Bernhoff, H. Power coefficient measurement on a 12 kW straight bladed vertical axis wind turbine. Renew. Energy 2011, 36, 3050-3053. [CrossRef]

38. Zanforlin, S.; Nishino, T. Fluid dynamics mechanisms of enhanced power generation by closely spaced vertical axis wind tur-bines. Renew. Energy 2016, 99, 1213-1226. [CrossRef]

39. Kelley, N.; Jonkman, B. A Stochastic, Full-Field, Turbulent-Wind Simulator for Use with the AeroDyn-Based Design Codes, Online Database. 2009. Available online: http:/ / wind.nrel.gov/designcodes/preprocessors/turbsim/ (accessed on 25 November 2020).

40. Giorgetti, S.; Pellegrini, G.; Zanforlin, S. CFD Investigation on the Aerodynamic Interferences between Medium-solidity Darrieus Vertical Axis Wind Turbines. Energy Procedia 2015, 81, 227-239. [CrossRef] 